\title{
DISCUSSIONS AND APPLICATIONS
}

\author{
(PR, Part II)
}

\section{I • FACT AND Form}

To BE AN ACTUAL ENTITY for Whitehead is to be fully formed, fully definite, with no indeterminations left unresolved. From the welter of what it could be, an actual entity decides what it will be: realizing certain potentials and positively excluding others; taking a definite stance with respect to everything in the ideal and actual worlds. Its real essence, structured by its associative hierarchy, comprises the full particularity of its status in the universe and of the universe in it: its unique way of housing and pervading this world populated by these actual entities. The result of the status decision is a new fact in the world, inexplicable in terms of anything outside its own self-creative process-ultimately its own reason for being what it is and what it is not. It presents itself to all subsequent occasions, therefore, as a new "given," irrational in the sense that its decisions are effected from within itself and are not mediated by any outside agency. It is "externally free" (PR 27). But its freedom is not to create itself ex nihilo. It still is what the others make it to be as a result of their own free decisions. The manifestation of its creativity is its own internal synthesis of what is given for it. Because of this self-functioning every actual entity has an element of exclusiveness. Its satisfaction cannot be tampered with, by either the addition or the subtraction of elements, without the destruction of the unique character of the entity. In its process the actual entity has established a fully determinate bond with each element in the universe, positively including that element in a determinate way in its nature or positively excluding (negatively prehending) it in a manner which makes the excluded item impossible for it. The freedom of an actual occasion is therefore both limited and limiting, conditioned by past achievements and conditioning future process, a decision arising out of previous deci- 
sions and provoking future decisions. Decision "constitutes the very meaning of actuality" (PR 43).

The decision which superjects givenness is a "decision amid "potentiality" " (PR 43): the real potentiality latent in the actual world stubbornly given for that occasion as a brute fact. This world is particular (unique to the occasion) and particulate (a disjoined multiplicity of individual facts apt for synthesis). In virtue of its individuality and that of its included members, it is actual; in virtue of its real potentiality for synthesis, it is a world. This real potentiality is ultimately tied to the primordial decision limiting the disjoined welter of possibilities to be conjoined possibilities. God's primordial nature is therefore the ideal realization of possibility, the ultimate activity conditioning possibility by its decision and grounding all subsequent decisions. As internal to God, it is a free and hence reasonless synthesis of eternal objects, limiting their indeterminate relevance to actuality and overcoming their mutual disjunction. As given for the world, it is the irrational conjugation and gradation of possibility which mediates objective givenness and subjective decision, making possible the synthetic unity of the emergent creature.

This mediation is first apparent in the objectification of actual entities. Each, though achieving a fully determinate, peculiar, and exclusive satisfaction shaped by a complex form, superjects ${ }^{1}$ that achievement to emergent perspectives as a plurality of potential objectifications, each of which is an element in the complex pattern structuring the entity. As has been seen before, every actual entity is a concrescence of prehensions, each seizing its datum with its own subjective form. A satisfaction is therefore a unitary feeling which represents the togetherness of a manifold of prior feelings. As will be seen in the analysis of Part IV of PR, these feelings are inseparate but separable. From the point of view of the physical pole of a concrescent entity, the objectification of a past occasion felt into the subject is one of these separable feelings as structured by the subjective form it possessed in the satisfied occasion. The subjectively formed feeling felt by the concrescent occasion is the aspect or modal limitation under which the past occasion enters the present-an aspect or modal limitation of the fully determinate unitary

\footnotetext{
${ }^{1}$ It will be noted that I occasionally employ "superject" as a verb-a usage not explicitly found in PR. My reasons for so doing are central to my reading of Whitehead, for I see that unless the superject be interpreted dynamically, as not merely "given for" but, more important, "acting in," a subsequent subject, then that subject is not the "cumulation of the past" but a mere "stage-play" (PR 237) about it. I interpret the past as "looming over" the present, as "pressing in," as "insistent," as "a flying dart hurled at the future," not as a passive, inert "given." I believe a case can be made for the fact that Whitehead himself leans toward this view, although this is not the place to develop my argument. I must admit, however, that many Whiteheadian scholars would disagree with my reading.
} 
satisfaction achieved in the past. As separable from that unity while at the same time inseparate from it, the objectification conveys the value achieved from past to present under an abstraction from itself which is not disconnected from the satisfied occasion. The metaphysical basis for this separable-inseparate character of a satisfaction lies in the primordial nature of God. These pattern elements, like the total pattern concretized in a satisfaction, are eternal objects, which, although selected from the other eternal objects comprising the total pattern, maintain a real relatedness to them. If this were not the case, actual occasions would be a synthesis of isolated fragments of their past and hence radically subjective and alone.

This doctrine can be clarified by reference to the fire example in the last chapter. If "red," the objectification of the fire, its modal existence for the eye, were not as an eternal object intrinsically bound up with the eternal objects "hot" and "crackling" in the complex eternal object "fire," then to appropriate "red" would be to appropriate it as an isolated possibility-redness-in-itself-and not as "red-fire-which-mustalso-be-hot-and-crackling." If appropriated in the former way, the "red" in the actual world of the eye would have no connection whatever with the "hot" and "crackling" in the actual worlds of the hand and ear. Not only the fire would have perished, but also the real togetherness of the forms which structured its definiteness. If formal togetherness is reduced to mere existential juxtaposition, the universe is fragmented into as many realities as there are perspectives, making any objectivity impossible. But if prior to any instantiation "red," "hot," and "crackling" are inextricably related in the eternal object "fireness," then the givenness of fire-as-red for an eye includes the potential relevance of the other eternal objects involved but not exemplified in this particular objectification. In other words, because the togetherness of eternal objects not merely is a product of finite process but represents a synthesis antecedent to all created fact, the "selection" in Whitehead's conception of "selective objectification" is not an annihilation of the relevance of alternatives. The way lies open for reverted conceptual feelings-a "secondary origination of conceptual feelings with data which are partially identical with, and partially diverse from, the eternal objects forming the data in the first phase of the mental pole" (PR 26). Every actual entity therefore actualizes a nexus of eternal objects whose togetherness is already ideally realized in the primordial nature of God.

The mediation of ordered and mutually relevant eternal objects is likewise responsible for the fact that the appropriation of various items in a public world can be synthesized into a drop of private experience. Eternal objects not only serve to objectify data; they also clothe the feelings whereby data are grasped, functioning as the subjective forms of feelings and in their togetherness constituting the private emotional 
complex. That they are sympathetic is a function of the subjective aim; that they are capable of being sympathetic is a function of their primordial togetherness in God. As a result of the ingression of eternal objects as subjective forms, feelings acquire a private character such that an actual entity can be said to "enjoy" its experience rather than merely to undergo it. There is thus no bare feeling, no absolute objectivity, no mere inheritance of influence from a causal past. Both physical and conceptual prehensions add not only their data to the satisfaction but their emotional character as well. Even in the case of negative prehensions which eliminate their data from feeling, the subjective forms add to the definiteness of the occasion.

The subjective forms arise under the influence of the subjective aim of the concrescence-the hypothesis prepared for the concrescence in God's synthesis of his primordial envisagement and his consequent physical assimilation of the entities in the actual world of the concrescence. From this synthesis arises the abstract value realizable from the perspective; this, from the standpoint of the perspective, forms a proposition with the nexus of the actual world, a lure proposed for feeling, to be concretized-i.e., its indeterminations solved by the concrescence. When the lure is finally realized, the fully determinate value achieved becomes a condition limiting subsequent creativity because of the real potentiality embodied in it. The initial valuation of eternal objects in the primordial nature provides a background of graded eternal objects against which the subjective aim is set. Without the background, actual entities would be Leibnizian monads, achieving autonomy but incapable of contributing that achievement to future process. The primordial nature undergirds the solidarity of the world, supplying the communal conditions which make individuality possible. It "constitutes the metaphysical stability whereby the actual process exemplifies general principles of metaphysics, and attains the ends proper to specific types of emergent order" (PR 40). Thus, despite the exclusive character of the satisfaction of an actual entity, despite its privacy, it can arise out of the equally exclusive and private achievements of the others in its actual world and bequeath itself as a new condition laid upon the future.

\section{II • The Extensive Continuum ${ }^{2}$}

A further limitation must be introduced into the realm of possibility in order to guarantee the solidarity of an actual world. In previous discus-

\footnotetext{
${ }^{2}$ Whitehead introduces the notion of the extensive continuum by means of a preliminary discussion of conscious perception. But to discuss perception at this point in the analysis requires that certain thus far unexplicated notions such as "society," "social
} 
sions of actual occasions, it has been mentioned that, as a result of the self-creative process, each occasion actualizes the drop of space-time which is its fully determinate perspective. In its satisfaction, it synthesizes the "there's" and "then's" in its actual world from the vantage point of its "here" and "now," thus producing the unique, perspectival "here-there," "now-then" relationships into which its concreteness can be analyzed. In the same manner as that in which the ideal realization of eternal objects in God's primordial nature had to be invoked to guarantee the metaphysical communality of occasions, an additional limitation of potentiality must be postulated as the condition for their physical togetherness. Without some more general uniformity, diverse, perspectival, spatio-temporal drops could never be coordinated to form a new occasion.

In grappling with the correlative problem in mechanics, Newton was forced to postulate absolute space-time as a container composed of an infinity of immovable, spatio-temporal positions with respect to which relative motion could be measured. Whitehead cannot opt for this explanation, for to him actual entities do not undergo "adventures" in spacetime. They literally do not move. Each finite satisfaction is fixed and unchanging: objectively immortal and resembling more the absolute spatio-temporal places of Newton than it does his bodies in relative motion. What is to be accounted for is not the relativity of motion but the solidarity of an actual world populated by entities "at rest" in their perspectival places. In other words, the spatio-temporal unity of an actual world needs grounding. Nor can Whitehead choose an explanation of a Kantian sort by postulating a synthetic activity of mind as the source of the spatio-temporal coordination of actual occasions; mind can unify only what is already given as unifiable, being in Whitehead's view merely a later, more complex phase in the concrescence of an occasion-a concrescence which, like all others, originates in the physical prehensions of the entities in an actual world. What Whitehead seeks is, therefore, neither something actual (such as an absolute space-time system in which events are situated) nor something purely subjective (such as an a priori form) but rather something which itself is an aspect of the real potentiality given for any concrescence.

He finds this in the notion of the extensive continuum as an overarching scheme of relational possibility of which the relativistic space-times

order," "personal order," "causal objectification," and "presentational objectification" be grasped in preliminary form. Rather than anticipate what will be fully elaborated in subsequent sections, I shall use a more general derivation of the necessity for and nature of the extensive continuum, which will be further amplified in the discussions of perception which follow. 
of actual occasions are further specifications. This coordination of spatio-temporal possibility is not to be construed as a geometric schema-for it is more general than geometries, which themselves, as metric, are perspectival. It is "one relational complex in which all potential objectifications find their niche" (PR 66). As a locus for potential objectifications, it is a continuum with infinite divisibility and unbounded extension, containing no singularities, no privileged "places," no asymmetrical relations, and no metric characteristics, for these are properties of actuality in its stubborn atomicity. In other words, it is not exemplified in actual occasions in its generality. Occasions particularize it, rupture it, specify its generality from their perspective. Yet the general coordination remains as the first limitation of the real potentiality for subsequent occasions-as a schema of possible spatio-temporal relations in terms of which the achieved drops of space-time in the actual world are coordinatable from the perspective of the concrescent occasion.

It must be carefully noted that this schema does not specify the idiosyncratic characteristics of the space-times peculiar to various cosmic epochs (e.g., that they be four-dimensional, five-dimensional, bichronal, etc.). These are further determinations introduced by the course of events in a cosmic epoch and are relative to the cosmic epoch in question. The determinations introduced by the extensive continuum are the more general conditions which must be shared by all dimensional systems if they are to be systematic and dimensional. ${ }^{3}$ These are the properties of extensity as such, irrespective of its dimensionality, and concern relations such as inclusion, connection, overlap, etc., without which any modality of spatio-temporal relatedness is impossible. The extensive continuum is therefore the "spread" of space-time conceived as the potential public relatedness of private relations in an actual world. When this spread is atomized and specified in a concrescence, it allows the multiplicity of the past to achieve the solidarity of one world for the concrescence and for the future. It provides a spatio-temporal mutuality which transcends the limitations of each perspective so that each actual occasion can pervade and house all spaces and all times.

\section{III • ORdER, SOCIETy, Organisms, AND ENVIRONMENT}

The descriptions of actual entities thus far built up from SMW and PR are still far removed from a description of the concrete world given

\footnotetext{
${ }^{3}$ For this reason, in Part IV of PR Whitehead is compelled to redefine the basic spatial notions such as "point," "line," and "plane" in purely formal terms not peculiar to our cosmic epoch.
} 
for human experience-the world of concrete, enduring yet changing objects. Actual entities have been described only in terms of their general character and relations to each other, not in terms of the more particular relations which join them together into atoms or stones or trees. An actual world has been spoken of only as a nexus of mutually implicated occasions. What has been left out of the previous discussions are the more specialized kinds of order which can be manifest in an actual world, those in virtue of which the concrescence relative to that actual world can achieve greater intensity in its satisfaction, greater importance and value for itself and for the future.

In general terms, order is that factor in an actual world which limits a concrescence, deciding for it what it can and cannot become. No actual occasion can outgrow its actual world, since it is an outgrowth of that world. This is the root meaning of givenness. The real potentiality, the real options offered a concrescence are settled for it by its antecedent world, by the limited potentialities for synthesis in the data. ${ }^{4}$

What differentiates order from mere givenness is the fact that an ordered world does not merely provoke a satisfaction, it promotes intensity in resultant satisfactions in view of the coordination already present in the data. This is not to say that every element in an actual world manifesting order is therefore bound up in the dominant order. Disorder is a necessary part of the given as well-the disorder introduced by mutually inhibiting or incompatible elements, which will have to be negatively prehended or synthesized as contrasts if an aesthetic unity is to be achieved. It is the proportion of order to disorder in an actual world which conditions the intensity of a resultant satisfaction, which intensity is the private aim of the concrescence, that which the entity seeks for itself-the subjective form or emotional tone of the satisfaction. Why this is so remains to be seen.

The intensity of a satisfaction is a function of the aesthetic structure of the concrete value or pattern exemplified in it. If, for example, the actual world of a concrescence is excessively diverse and uncoordinated, the resultant synthesis will have a trivial value, in that the various feelings do not strengthen each other. In Whitehead's terminology, it will manifest an excess of width without reinforcing narrowness. (Cacophony as opposed to harmony, randomly repeated sound as opposed to rhythm serve as illustrative analogues.) On the other hand, an excess of identity among the original data produces an unaesthetic vagueness

\footnotetext{
${ }^{4}$ One cannot make a silk purse out of a sow's ear; but one could make a leather wallet, or a pouch. "Imperious Caesar, dead and turn'd to clay, / Might stop a hole to keep the wind away" (Hamlet, V.i.235-36) because he embodied that potentiality (among others) for the future.
} 
in the satisfaction: the many are integrated into a formless one. In this instance, the defect is an excess of narrowness. An intense satisfaction arises from the proper balance of width and narrowness, a balance achieved through the progressive unification of the incompatibilities in the manifold in terms of contrasts and rhythms through which the necessity for negative prehension is overcome. An intense satisfaction will therefore manifest width in its earlier stages and progressively simplify that width in the later stages. It resembles a painting with a carefully detailed foreground set against yet growing out of a vaguely discriminated background. The right kind of narrowness is essential if the painting is not to become a cartoon; the right kind of width and vagueness if it is not to degenerate into chaotic busy-ness.

Thus the aesthetic value of a satisfaction finds its inspiration or lack of inspiration in the order-disorder given for it in the environment. That each actual world is unique to the occasion arising out of it entails that there be no absolute or ideal order in a universal sense; there are only the limited orders relative to perspectives and their actual worlds. Nor can an actual entity achieve an absolute ordering of its own given. All attainment is partial, involving the elimination or trivialization of elements unsynthesizable (qua disorderly) from the perspective. However, the partiality of any finite attainment is the ground for subsequent creative endeavor in which the disorderly elements may be positively unified in the order of a new perspective.

Although no absolute order is possible, actual worlds will exhibit dominant orders relative to them: the "moral order" proper to a given culture, or the "physical order" dominant in a cosmic epoch. These, though not absolute in either their universality or their dominion, provide an emerging entity with an environment whose incompatibilities have been partially overcome through their shared order, an environment whose further synthesis can evoke a more intense satisfaction than that growing out of an environment not already structured. The right order and the right disorder are therefore the conditions for the possibility of intensity. Both too little and too much order evoke low-grade satisfactions: the former, because it necessitates wholesale rejection of incompatible data, thus impoverishing the content of the satisfaction; the latter, because it compels uncreative reiteration of the overdominant pattern, thus robbing the perspective of its originality. The doctrine of social order is Whitehead's interpretation of the ways in which this fine balance is maintained in the world.

Social order is not an addition to the doctrine of actual entities, tacked on to make aesthetic achievement possible; it is a special case of the organic interfusion of actual entities, reinforcing the mutual connectedness of members of a nexus by the exemplification of a common ele- 
ment of form in each-the defining characteristic of the social nexus. This is not to imply that the satisfactions of members of a society are identical. In their full particularity, they are still diverse. They share in common, however, certain general characteristics which mediate and canalize their diversity, making it a relevant diversity, one unified through the contrast-in-identity of the various members. Thus, the presence of a defining characteristic lends an order to a social environment which is not found in a nexus. For a member arising within a social context, the shared form in the data allows the diversity (disorder) to be aufgehoben rather than negatively prehended; hence more complex integrations and more intense satisfactions are possible. "The dominance of societies . . . is the essential condition for depth of satisfaction" (PR 93).

A nexus becomes social when the already present similarities among its members become important for them as a group. ${ }^{5}$ That set of similarities-a complex eternal object-gains significant relevance in the objectifications of the members, and is inherited by new members arising in the social environment, who reproduce the defining characteristic in their own definiteness and further propagate it, thereby ensuring analogous similarities in the future. "Thus a society is, for each of its members, an environment with some element of order in it, persisting by reason of the genetic relations between its own members" (PR 90).

The endurance of a society is temporally limited, however. There are no self-contained, "simply located" societies, needing nothing but themselves in order to survive. Every society exists within a wider framework, needing a background of social order to ensure its continuance by supplying the more general characteristics necessary for the maintenance of its specialized characters. Members of the included society are members of the larger society as well, and depend on the more general characters in the larger environment as the base for their specialization. ${ }^{6}$ The same must be said for the larger environment as well. The most general society of which we are aware is that manifesting the order of protonic and electronic occasions peculiar to our cosmic epoch. ${ }^{7}$

${ }^{5}$ This importance would arise because of conditions in which the embryonic society finds itself.

${ }^{6}$ For example, a cell in an organ has specialized characteristics in virtue of its inclusion in the organ, characteristics not shared by cells in other organs. But in addition to being a liver cell, for instance, it is likewise a bodily cell and shares certain general characteristics with all other bodily cells. Without these more general characteristics, it could not support its specialized ones. Its social environment is the liver and the body.

${ }^{7}$ Leaving metaphysics aside for the moment and concerning himself solely with the spatio-temporal characteristics of occasions, Whitehead hypothesizes that the extensiveness manifested in this cosmic epoch may itself be a specialization within a broader 
Actuality therefore presents itself as a nest of social environments providing more and more complex orders for included members. This nest must not be conceived after the model of nested boxes, however. In such a spatial construct, the environment would be construed as external to the environed society. The organic model is the only apt one, for, in this, all nested environments pervade each other, so that an actual entity receives objectifications from the members of all environing and environed societies in the nest.

An unfavorable change in the proximate environment can lead to the collapse of an included society, rendering its members incapable of propagating the defining characteristic. This collapse is not to be interpreted as the annihilation of the members. The society vanishes when the defining characteristic is no longer a relevant, important item in the satisfactions of its members. The endurance of societies is therefore epochal: they arise, flourish, and decay as a function of the background order in the environment, with societies requiring more specialized environments having a higher mortality rate than more primitive ones. Even the widest society-the cosmic epoch-is itself mortal, being set against a background of disorder which will eventually overcome it. This does not spell its annihilation any more than its arising entailed creation. Both birth and death are marked by the incoming of a new order, not by the initiating and cessation of existence. God creates by providing forms relevant to self-creative factualization, not by calling fact forth from nothingness.

This fundamental description of social order as the genetic inheritance, display, and propagation of a defining characteristic in a nexus of actual entities is strictly applicable only to entities arising in a physical field in empty space-those intermittent flashes of existence which manifest no temporal continuity of inheritance relations and hence are not particles in the sense in which physics uses the term. (They are not enduring objects.) The notion of temporal endurance demands a further specification of "society," transforming merely social order into "personal order." What differentiates the latter is the fact that the members of the nexus are arranged in a one-directional series via a linear propagation of the defining characteristic. Each occasion of the thread arises out of and sums up its own history in a peculiarly intimate way, and is provoked to reiterate its past character in the present, thereby allowing us to speak of particles, wave trains, and the like as enduring entities.

framework of order: a society of alternative geometries each determined by the congruence-definitions which hold within it. This geometric society forms a subset of the society of pure extension whose defining characteristics are the relations manifest in the extensive continuum. The mind cannot push the boundaries further back than this. 
What endures through a lapse of time is not a factual actual entity, but a defining characteristic, an eternal object reiterated in a thread of occasions, enabling each to sum up its "personal" past in a peculiarly intimate way.

The macro-objects of experience are social organizations of strands of such personal order woven together by an additional defining characteristic. In Whitehead's language, they are corpuscular societies. These may vary in complexity from the simple coordination of personal threads manifested in an atom to the more and more complex groupings of simple corpuscular societies as subsocieties in higher societies, represented by molecules and crystals, cells and organisms. ${ }^{8}$

A corpuscular society provides a highly favorable environment for members arising within the included personal threads. Their data exhibit a massiveness of shared order, which promotes both intensity in the resultant satisfactions and stability for the social organization. Each included occasion in its grasp at intensity inherits and ratifies its position in the whole, and the whole thereby tends to endure. This same massiveness of order inhibits the originativeness of the members, however, since it "binds any one of its occasions to the line of its ancestry" (PR 104), thereby oversimplifying diversity in the environment, blocking out detail not relevant to the dominant order. As a result, included entities are not sensitive to environmental change-it is either negatively prehended or reduced to trivial relevance - and cannot react adaptively to it. Inorganic structured societies are capable of long endurance only if the environment is relatively stable.

If the society is specialized with respect to the presence of certain characteristics in the environment, its endurance is more a function of environmental stability than that of an unspecialized society. The former may offer higher-intensity satisfactions than the latter because of the increased complexity of the defining characteristic, but it nevertheless breeds reactionary, maladaptive members which are ultimately at the mercy of the environment, to be either dominated by its order or rendered "stateless" by its disorder. The appropriate response to the problematic of a shifting environment cannot be made from within an inorganic society, since in such a society the new can be cast only in the mold of the old.

Life is the alternative response to change. It manifests itself in an escape from inheritance, as "a bid for freedom" (PR 104): freedom from the pressure of the past and for reaction dictated by the present-

\footnotetext{
${ }^{8}$ That the latter pair cannot be interpreted solely in terms of social inheritance will be dealt with shortly.
} 
for the capture of intensity and the grasp at vivid immediacy. By definition, therefore, life is antisocial. Living occasions form non-social nexuses, not societies or personal orders. They are mutually implicated but not mutually determining, representing the triumph of final over efficient causality. Since they are unbound by conceptual inheritance, living occasions can grasp novelty as novel and can initiate novel, adaptive responses through the increased operations of their unfettered conceptual pole. Life manifests a degree of autonomy not found in the inorganic world of corpuscular and structured societies. Yet its very autonomy makes it paradoxically the most destructive as well as the most fragile of forces. Without a highly structured environment to pattern its data and assimilate its reactions, it is merely a moment of valueless, anarchic disorder, resembling a revolutionary so radical as to eschew any contact or communication with the society he revolts against, thereby forfeiting both the platform and the fruits of his revolt.

If a living occasion is to achieve any value in its satisfactions-i.e., in itself, for the others, and for the totality-it must originate from within a highly structured social context which orders its data in such a way that environmental disorder (novelty) is included as relevant contrast rather than dismissed in negative prehensions, and must superject its novelty to an environment complex enough to withstand and appropriate it. ${ }^{9}$ Life is impossible outside the shelter of a structured society with a certain amount of complexity. Within that context, a living occasion can be sensitive to the social past, since that past forms part of its actual world, yet not be bound by it; and at the same time can bequeath relevant novelty to the sheltering society, thus ensuring and enhancing the organism's survival in the welter of change.

A structured society harboring living occasions is termed living when the living nexus is regnant. However, the notions of "harboring" and "regnancy" must be carefully explored to avoid their being interpreted in classical soul-body terms. Inasmuch as living occasions are not social either in the generic sense (as unified by a defining characteristic) or in the more special sense (as possessing personal order), they are not elements in the enduring structural pattern of the host organism; nonetheless the data patterned by occasions arising within that structure are available to them, constitute their actual world, and are the source for their intense physical experience. The entirely living nexus is therefore situated within the bodily society but not as a structural and hence social element. For this reason, a living occasion is not bound to reiter-

\footnotetext{
${ }^{9}$ Too much novelty may destroy the "animal body," the way a runaway auto-immune response can "kill" its host.
} 
ate the defining characteristic dominant in its bodily region and can react spontaneously to the data.

The reason for the living occasion's ability to superject novel responses to the data is not attributable to some inner characteristic of the living occasion. All actual occasions are exactly the same in that they are what the real potentiality of their environment allows them to be. Life arises, therefore, as a function of environmental data, requiring complex data "on the edge of a compatibility beyond that to be achieved by mere inorganic treatment" (PR 106), if it is to arise at all. In the realm of the inorganic, environmental disorder is either negatively prehended or integrated in faint contrasts. The eternal objects embodied in the disorderly elements are not directly prehended by a social occasion: they become an element in its definiteness either through the integration of the subjective forms of the negative prehensions (in which case they are not operative constituents in the occasion or for the future) or as variables, "x's," in the contrast pattern (in which case though not operative in the present save as bare relata in the contrast, they are potentially operative in the future, having achieved a minimum of ingression in the present). A future occasion, in grasping the exemplified contrast in its feelings, can initiate reverted feelings ${ }^{10}$ of the eternal objects, seizing them in pure conceptual feelings which "recognize" the disorder-novelty and appropriate it via novel subjective forms. Since these reverted feelings must be integrated with the feelings of the orderly data, the subjective forms of the latter feelings are modified (according to the Category of Subjective Unity) so as to be sympathetic to those of the former feelings; out of the totality of feelings a drop of relevant novelty emerges, to be superjected to the "animal body"- -the structured society harboring the living occasions. It is assimilable by the animal body since it does not mark a total break with the social, bodily past. ${ }^{11}$ In other words, it is the organization of the data which is responsible for the origination of non-social occasions: for the intensity of their experience and for their ability to escape the necessity of inherited modes of response and to respond originatively. It is this novel yet historically relevant datum superjected by a living occasion which gives its host the adaptive flexibility which is the hallmark of a living body.

Living occasions arise, therefore, wherever such environmental con-

${ }^{10} \mathrm{~A}$ reverted feeling occurs when the feeling of one eternal object results in a derivative feeling of other eternal objects relevant to it. Thus, a feeling of a contrast may elicit a feeling of the contrasted eternal objects.

"Of course, the case described above is an oversimplification of vital processes, but it serves to illustrate in ideal outline the mechanism at work. 
ditions prevail within the body- "in the interstices of each living cell, and in the interstices of the brain" (PR 105-106), surrounded by the inorganic lattice and enabling it to function organically. Thus living occasions populate the body without any historical or social continuity among themselves, appearing wherever the complexity of the data can evoke them. Therefore, it is totally inappropriate to speak of an enduring vital principle animating a body. A living occasion can have no history, no inherited mode of response, to shackle it (save the history of the animal body and the ambient environment) if it is to be free to introduce relevant, novel solutions to novel problems.

An entirely living nexus becomes regnant in a stuctured society and enables that society to be termed living when the contributions of that nexus become important for the society. By the same token, an occasion is living when novel forms assume importance in its satisfaction. Therefore, no sharp line of demarcation between the organic and the inorganic, between the living and the non-living, can be drawn. One can speak of thresholds of life, however-but not with any exactitude.

The operations of a regnant, living nexus disturb the ordinary functionings of the inorganic host. In a sense, the physical laws which form part of the defining characteristic of the subservient inorganic societies are modified by the actions of the living members. As Whitehead said in SMW, "The electron blindly runs either within or without the body; but it runs within the body in accordance with its character within the body; that is to say, in accordance with the general plan of the body, and this plan includes the mental state" (SMW 79). A breakdown in inherited social bonding - in the statistical, physical laws keeping the society "together" - comes about in the transmission of energy across the interstitial empty space ${ }^{12}$ when it harbors living occasions, thus producing an instability and disruption in the ordinary "blind-running" of the body's inorganic societies. Chemical dissociations occur which would not take place outside a living body and which require repair if the bodily society is not to lose the structure it needs to support the living occasions. Therefore, a living organism continually requires food: inorganic societies "robbed" from the ambient environment to repair the inorganic damage life causes, returning the disturbed region to chemical stability. This larcenous character of living organisms orders them in systematic social relations of food-chains and eco-systems, making nature herself social in the ordinary meaning of the term. ${ }^{13}$

12 "Empty" means containing no permanent structures, not sheer nothingness.

${ }^{13}$ Nature is social in Whitehead's technical sense, in that the basal society is the society of electromagnetic occasions which characterizes this cosmic epoch. An organism is not in this macro-society as in a container; it is a regional budding of this society in more complex forms. 
In living organisms of sufficient complexity, strands of personal order may appear among the living members, arranging them into "living persons" with personal histories. It would seem at first glance that such an ordering would vitiate the originativeness of occasions within such threads, and a thread itself would resemble a particle. If what were inherited in the strand were a defining characteristic of the inorganic type, i.e., a determinate mode of response, this would certainly be the case. However, the defining characteristic of a living occasion is not the structure unifying the content of its satisfaction but the structure of that structure: a lifestyle or personality. In the same sense as an artist's style unifies his life's work without inhibiting his genius, the defining characteristic of a living person canalizes the novelty achieved in the many occasions of its existence-making it more intense because of the continuity attained with past novelty. Through the origination within it of a personality with historical continuity, a living organism is further protected from the possibly rampant and destructive originality of the included living occasions. The living occasions themselves achieve greater intensity in their satisfactions. Thus creativity is mated with historic continuity, originality with inheritance, in overcoming the essentially anarchic character of life.

With these various notions, the model of a high-grade organism emerges as a complex of subordinated, inorganic societies and subsocieties protecting and protected by a regnant personality. ${ }^{14}$ "Thus in an animal body the presiding occasion, if there be one, is the final node, or intersection, of a complex structure of many enduring objects" (PR 109). If the organism is envisioned as a nest of concentric circles, the presiding occasion is the center point, receiving as its data the patterned and repatterned data superjected by the various levels of the bodily society. "The harmonized relations of the parts of the body constitute this wealth of inheritance into a harmony of contrasts, issuing into intensity of experience. The inhibitions of opposites have been adjusted into contrasts of opposites" (PR 109). In the case of man, the human mind at any occasion of its existence is "conscious of its bodily inheritance. There is also an enduring object formed by the inheritance from presiding occasion to presiding occasion. ... This route of presiding occasions probably wanders from part to part of the brain, dissociated from the physical material atoms" (PR 109), ${ }^{15}$ arising in the region receiving

\footnotetext{
${ }^{14}$ In the case of lower life forms, the personal strands are more loosely structured in a "democracy."

${ }^{15}$ This "consciousness of bodily inheritance" is critical to Whitehead's epistemology. What the "soul" primarily knows is the antecedent physical states of the body, which themselves are modal appropriations of the ambient environment.
} 
the most input from the bodily system. When cortical activity is at a lower ebb, its dominance may fade for a time and be replaced by more democratic relations among living strands.

\section{IV • The Modal Theory of Perception}

When conscious perception is discussed, it must be borne in mind that for Whitehead consciousness is a subjective form qualifying the experience of the living occasion or thread of occasions regnant in a highly complex society which provides the data for the percipient occasion's feelings. Perception is not therefore an exception to the doctrine of actual entities and of society already laid down; rather, it represents a further refinement in feeling possible to a concrescence because of the real potentiality of its data: a mode of experience which is a further synthesis of the data out of which the percipient occasion arises. The immediate environment for the percipient occasion is the animal body, with its manifold of interrelated and hierarchically structured subsocieties, which likewise harbor living occasions. The data from these societies (or from some of them) as further correlated by the society of neurons in the brain form the actual world from which the percipient occasion arises, the actual world whose final synthesis the percipient $i s$, and to which it partially conforms in its self-creative process. Therefore the classic image of perception as the soul's immediate and concrete grasp of the outside world via the senses must be carefully qualified if it is not to distort the model Whitehead creates. The outside world is indeed an element in the actual world of the percipient occasion, but its data have been structured and restructured by the occasions in the bodily society, particularly in the sensory organs and central nervous system, so that in no way can it be said that perception is a concrete grasp of an external object. It is abstract: in a temporal sense, many operations removed from the physical appropriation of environmental causality by the basal societies in the animal body; in the genetic sense, many phases removed from the physical experience of the percipient occasion in the brain. The simplistic view of perception which takes it to be the direct experience of the qualitative aspects of environmental objects is the metaphysical naivete which rightly provoked the Humean and Kantian critiques-a prime example of the Fallacy of Misplaced Concreteness.

In PR, Whitehead gives two accounts of perception: $(a)$ the more general analysis of the three modes it takes (presented in PR II, Chapters IV-IX, and again in S); and (b) a situation of perception in the genetic and coordinate analyses of a concrescence presented in PR III 
and IV. The two accounts are not contradictory, though their mutual consistency is not explicitly demonstrated in PR. It may be the case that Whitehead realized that detailing the specifics of the various modes in the genetic and coordinate accounts would make the complexity of those accounts so massive as to be impenetrable, and left the task to the reader.

The ontological basis of perception is the interpretation of an actual entity as a drop of experience, which interpretation has been detailed in previous chapters. Since experience is the self-realizing process of any actual entity, conscious experience is merely a further refinement of the more fundamental modes of experience (physical and conceptual functioning) and not a radically new activity introduced by a percipient. It is a more sophisticated form of "the "self-enjoyment of being one among many, and of being one arising out of the composition of many" " (PR 145). To keep a discussion of conscious perception from falling into Misplaced Concreteness, it is necessary therefore to insert it into the wider framework of the becoming of experience, so that its genetic relatedness and continuity with basal physical and conceptual experience can be maintained.

Whitehead sees an actual entity as moving from the givenness of its data, which provide its objective content and real potentiality as decided by occasions in the past, to the superjection of its own decision to the future, via a non-temporal concrescence of phases culminating in the satisfaction or closing up of the entity. ${ }^{16}$ In this process, the data, under limitations determined by their own decisions, are met with "the rush of feelings whereby second-handedness attains subjective immediacy" (PR 155). The indeterminations in the data-how the many are to be felt as one, how they are to be objectified and subjectively felt-are solved in the concrescence.

Every individual objectification in the datum has its perspective defined by its own eternal objects with their own relevance compatible with the relevance of other objectifications. Each such objectification, and each such complex of objectifications, in the datum is met with a correspondent feeling, with its determinate subjective form, until the many become one experience, the satisfaction [PR 154-55].

\footnotetext{
${ }^{16}$ See the schema of these phases given in Figure 3. Unfortunately, any spatial representation of a concrescence must perforce give the impression that the phases succeed one another in linear order from initial data to terminal satisfaction. Therefore, the reader must bear in mind that no phase is ever completed and passed beyond. Each reaches completeness only in the satisfaction, the fully determinate drop of space-time which closes up an entity's process of self-actualization. "There is a becoming of continuity, but no continuity of becoming" (PR 35).
} 


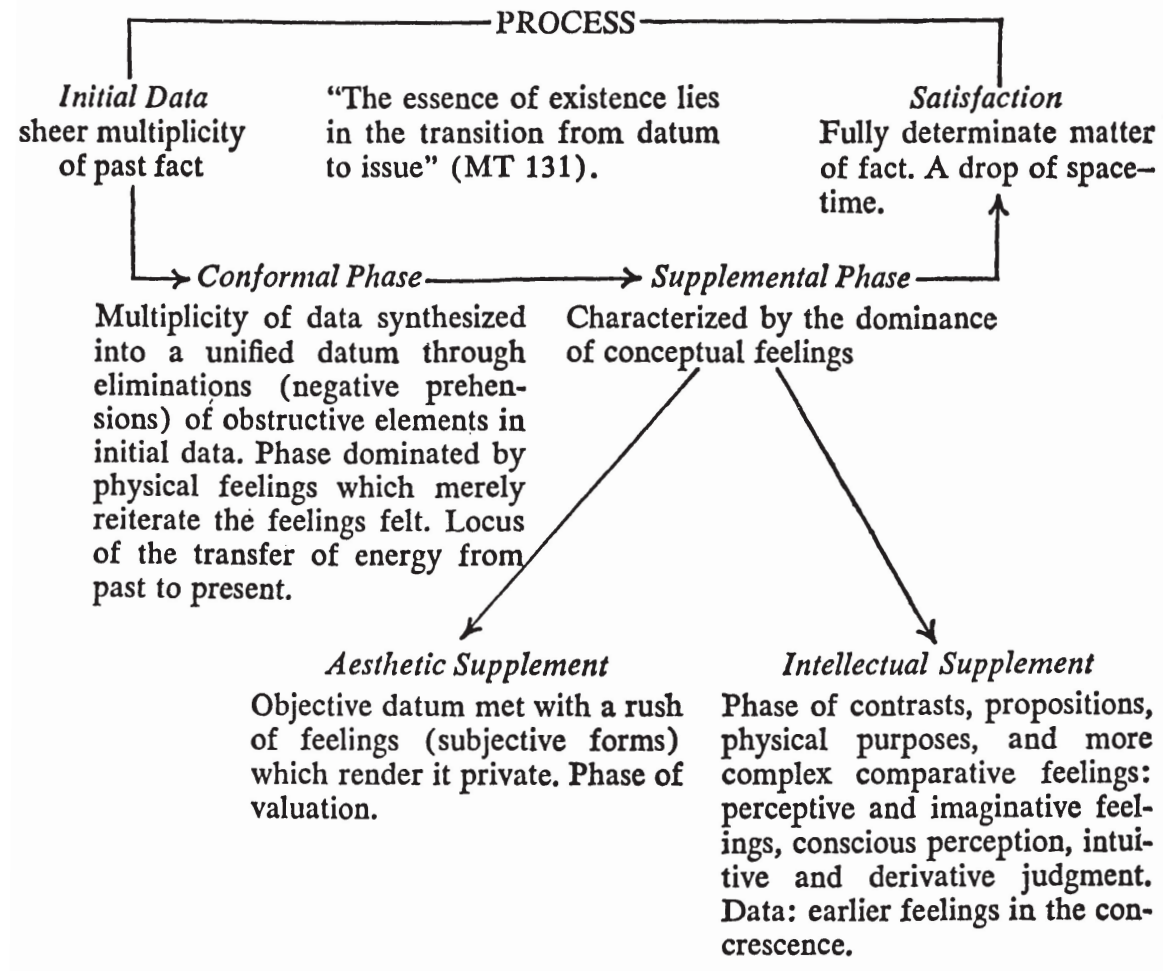

FigURE 3

Eternal objects have a twofold functioning with respect to this subjective appropriation of objectivity: $(a)$ they structure the objectifications of the data; and $(b)$ they qualify the subjective feelings of those data, ingressing as their personalizing subjective form. In the initial phase of a concrescence - the phase of objective conformation-the eternal object qualifying the subjective form reproduces the eternal object in the objective datum: thus a concrescence originates as a feeling of the feeling of another, as a subjective re-enactment or reiteration of what is objectively given for it. In the supplemental phase, so called because additional eternal objects ingress to "supplement" those given in the data, the diversity in the data is overcome through the mediacy of sympathetic subjective forms, eternal objects conceptually felt as compatible with each other and hence promoting the realization of subjective unity. In the initial phase of the supplement, called aesthetic because it has to do with the personalizing harmonization of the given, these subjective forms are predominantly emotional and purposive in character, 
determining the relative importance of items in the data with respect to the guiding ideal of the concrescence-its subjective aim. In the intellectual supplement, the emphasis shifts to further integrations of already grasped material-in contrasts, rhythms, comparisons, and the like through which feelings previously arising in the concrescence are adjusted and wedded into more complex unities. It is in this stage that consciousness arises as the subjective form of certain feelings. As the subjective form of a supplementary feeling, what it illumines are the feelings in the stage in which it arises, and not primarily the physical experience from which the concrescence originates. If the latter is rendered conscious at all, it is illumined vaguely and derivatively, in proportion to the relevance it still retains to the concrescence. Despite its remotion from the basal, physical experience of the percipient, conscious perception is nevertheless an outgrowth of it, and hence is rooted in "stubborn fact" as "the cumulation of the universe and not a stageplay about it” (PR 237).

\section{a. Perception in the Mode of Causal Efficacy}

The most primitive form of awareness for Whitehead is not the vivid display of the ambient environment normally termed sense perception, but the vague feeling of causal presences which he terms "perception in the mode of causal efficacy," or "sense reception." In an organism which achieves a significant consciousness of its present environment (sense perception in its ordinary meaning - to be discussed later), the causal perception is rendered conscious as well, as the vague awareness of causative agencies underlying and provoking the vivid display. For organisms without such consciousness, causal efficacy remains unconscious-as the basic receptivity of the percipient occasion manifest in its conformal and aesthetic phases.

In the ideally simple case of one concrescent actual entity feeling one objectified actual entity, the datively functioning eternal object whereby the past actual entity is objectified ingresses into the relationship as its subjective form, making the concrescent feeling conform to the feeling felt. A transition of feeling from entity to entity, from past to present, comes about as a result of the two-way functioning of this sort of eternal object, called by Whitehead a sensum. It is important to note that the term is used here in a sense more primitive than that normally employed in epistemology. It refers to an emotional feeling-tone which is inherited by the concrescent subject from the object, not the vivid colors, sounds, etc., displayed in ordinary conscious perception. A sensum is simply the primordial form of the subject-object relationship, a simple eternal object of zero width, not involving any lower-grade eternal ob- 
jects to make possible its ingression. It is the form of the efficiency of the object, superjected by the object and grasped into itself by the subject, the "kind" of energy decided for and felt by the concrescent occasion.

The conformal phase of any actual entity is a reception and coordination of sensa through the mutual sensitivity of their forms, ${ }^{17}$ so that the multiple re-enactive feelings can become the unified experience of one subject and hence relevant to future concrescences. These feelings are blind, vague, and heavily emotional, concerned with "a beyond which is determinate and pointing to a beyond which is to be determined" (PR 163). Hence there can be a transmission of feeling from past to present to future through the mediation of sensa which allow past efficiency to enter the constitution of present subjective immediacy. In the event that a manifold of causal influences is objectified (and hence appropriated) by the same sensum, the multiplicity is only vaguely felt, the eternal object being transmuted as derivative from a more generalized, regional source. In accordance with the Category of Transmutation, ${ }^{18}$ such a feeling has a vector character and a quantitative intensity proportionate to the number of reinforcing point sources of energy in the region. These regional feelings attain importance in higher modes of perception, for the present counterparts of those regions are what are vividly illustrated via the geometry and sense qualia of sight, hearing, etc.

When this oversimplified account of causal perception is amplified as a description of the receptive phase in human experience, it must be borne in mind that the experience described is that of the final percipient: the living occasion in the brain assuming temporary dominance because of the richness and complexity of its data. Its proximate actual world is the neuronic society in the brain, which itself receives data from the nervous system, other bodily systems and organs, and ultimately from the external environment. We are dealing therefore with historic chains of objectifications stretching from the external environment to the final percipient or regnant monad-chains of transmission of feelings, routes of sensa. Depending on the subjective aim of the regnant occasion and also upon conditions in the environing societies,

\footnotetext{
${ }^{17}$ This sensitivity has its ground in the gradation of eternal objects in degrees of relevance to any possible perspective accomplished in the primordial nature of God.

${ }^{18}$ By the Category of Transmutation, "When . . . one and the same conceptual feeling is derived impartially by a prehending subject from its analogous simple physical feelings of various actual entities in its actual world, then, in a subsequent phase of integration of these simple physical feelings together with the derivate conceptual feeling, the prehending subject may transmute the datum of this conceptual feeling into a characteristic of some nexus containing those prehended actual entities among its members, or of some part of that nexus" (PR 27).
} 
certain parts of this route-certain links in the chain-are enhanced, and others reduced to trivial relevance. The important links-the external region and the end organ--enter the experience of the final percipient as significantly objectified. The " "eye as experiencing such and such sights" " (PR 118) is the intensely felt objectification in visual perception; the route to and within the brain and the route through the external environment is de-emphasized. Therefore, "the predominant basis of perception is perception of the various bodily organs, as passing on their experiences by channels of transmission and of enhancement" (PR 119). The "human body is to be conceived as a complex 'amplifier' ..." (PR 119) of signals from within and without. What is being enhanced and amplified in the bodily route is vector feelingtone-i.e., sensa, the causal objectifications of past occasions in the external and internal routes.

The enhancement consists in the supplementation of the data by means of the intensification of the transmitted sensa accomplished through transmuted feelings and through the explosion of novel, reverted sensa resulting from the operations of living occasions in the route. Thus, the route through the animal body exemplifies both the transmission of vector feeling-tone from the environment and its own additions to the inherited data, e.g., the "datum transmitted from the stone becomes the touch-feeling in the hand, but it preserves the vectorcharacter of its origin from the stone" (PR 120). The living occasions in the hand experience the multiplicity of causal influences from the corpuscular stone-society, conform to them, transmute that experience to an experience of the stone-nexus-as-one, to which is attributed the stone-causality. They then revert the stone-feeling to a touch-feeling with which they objectify themselves to subsequent members of the bodily route. These occasions further enhance the relevance of the reverted touch-feelings. The final percipient in the brain inherits these enhanced sensa, transmutes them as objectifications of the hand-nexusas-one, vividly experiences the hand as experiencing the touch-sensum while derivatively and vaguely experiencing the stone as environmental source of the reverted sensum to which it is genetically related. The novelty which enters via this reversion is the sensum "touch feeling," an eternal object relevant to but not identical with the original sensum transmitted from the stone region. There is, thus, both repetition and origination going on in the route from the stone to the percipient occasion: (a) the conformation of each occasion in the bodily route to its immediate bodily past and to the more remote past of the ambient environment; and (b) the origination of transmuted and reverted feelings in the living occasions of the route, whereby the inherited sensa are enhanced and translated into terms relevant to the organism. Perception in 
the mode of causal efficacy emerges as "perception of the settled world in the past as constituted by its feeling-tones, and as efficacious by reason of those feeling-tones" (PR 120). It is present functioning as limited and conditioned by the environmental past, yielding the sensitivity to environmental influences noticeable in low-grade organisms. ${ }^{19}$

On the human level, where causal efficacy is derivatively illumined by the light of ordinary sense perception, it constitutes the vague fringe surrounding the vivid perceptual display. It is experienced as an emotionally charged feeling of the presence and pressure of the bodily and external environments: "the terrifying sense of vague presences, effective for good or evil over our fate" (S 43); "insistent, . . . haunting, ... unmanageable," ... "heavy with the contact of the things gone by, which lay their grip on our immediate selves" (S 43-44).

In the dark there are vague presences, doubtfully feared; in the silence, the irresistible causal efficacy of nature presses itself upon us; in the vagueness of the low hum of insects in an August woodland, the inflow into ourselves of feelings from enveloping nature overwhelms us; in the dim consciousness of half-sleep, the presentations of sense fade away, and we are left with the vague feelings of influences from vague things around us [PR 176].

It is the same sense of looming, overpowering presences which terrified Wordsworth in his youthful night voyage on the lake (see The Prelude, I.355-400). The feeling presents no sharply defined geometric arrangement of the causal presences felt, no discrimination into clear-cut objects with determinate spatial positions; it gives merely a sense of the vague yet controlling "aroundness" of the environment with vague, vector regions from which stream important influences. The causal feeling of the bodily environment is less vague, discriminating itself into clearer feelings of efficacious bodily organs with their general spatial location and relationships. It is this sense of the "withness" of the body, of the fact that we touch with the hand, see with the eye (these organs having been significantly objectified in the route), which will ultimately ground the objectivity of sense perception. We perceive because we receive, and know that we receive because we are vaguely aware of receivers and of the reception.

Despite the vagueness of perception in the mode of causal efficacy, it is the perception of what is the dominant focus of our interest, of the important factors in the environment which spell survival or destruction

\footnotetext{
${ }^{19}$ For example, heliotropism in plants and reflex behavior in lower animals represent an "awareness" (not in the fully conscious sense of the term) of the relevant causal influences in the organism's past.
} 
to the organism. Without these vague, peripheral yet inescapable feelings, sense perception could have no more objectivity than that of a dream or of the flickering images on a television screen:

these controlling presences, these sources of power, these things with an inner life, with their own richness of content, these beings, with the destiny of the world hidden in their natures, are what we want to know about. As we cross a road busy with traffic, we see the colour of the cars, their shapes, the gay colours of their occupants; but at the moment we are absorbed in using this immediate show as a symbol for the forces determining the immediate future [S 57].

The show, taken in itself, leads nowhere, leaving us locked in an isolated present; the vague feeling of past agencies leads us from the causal past into a future-directed present, in which adaptive responses can be forged to modify that future creatively. Causal efficacy permits a present enjoyment of past agency, whereby that agency can become effective in the future. It is "our general sense of existence, as one item among others, in an efficacious actual world" (PR 178).

\section{b. Perception in the Mode of Presentational Immediacy}

The second mode of perception-the mode of presentational immediacy-is difficult to isolate in its pure state, for, with the exception of certain instances of illusion or hallucination, it never exists in its purity but always as integrated with the causal mode. By the same token, pure causal efficacy is difficult to isolate in human experience because of the importance presentational immediacy has assumed for man. The mixed state-symbolic reference-is the ordinary component of human consciousness. But since, in ordinary sense awareness, the "show" is vivid (the gray shape), and the causal influx vague and ill-defined (the felt influence of the stubborn, factual stone-nexus), philosophers tend to overlook causal efficacy and to identify sensory awareness with presentational immediacy, thereby opening the door to the host of epistemological problems which beset philosophy from Descartes to Kant.

When this form of Misplaced Concreteness prevails, it is quite logical to equate perception with the subjective entertainment of universals whose origins are unknown. As a result of the mis-equation of presentational immediacy with conscious experience and of the more fundamental mis-identification of experience with conscious experience, the experient becomes permanently locked in the movie theater of the mind, endlessly watching a parade of images essentially unconnected either with each other or with an external, active world. Esse est percipi and nothing more. Locke's vague notion of "power" was an attempt to bridge the gap between conscious experience and reality, but it fell vic- 
tim to Hume's assault. In asserting that sensory awareness is a budding of a more primordial physical experience shared by all actual entities, Whitehead overcomes the phenomenon-noumenon bifurcation and objectively grounds human awareness, recognizing that although it may be the most primitive form of judgment, ${ }^{20}$ it is nevertheless an abstract modality of experience. In the subsequent discussions of presentational immediacy, it must be continually borne in mind, therefore, that Whitehead is deliberately isolating this mode of perception from its existential context as an outgrowth of causal efficacy, but that this isolation is methodological and not ontological.

When presentational immediacy is examined, the first characteristic which becomes apparent is that a different mode of objectification is at work here. Causal efficacy concerns itself with causal objectifications of the antecedent world, with past facts considered as operative in the present and as leading to a future. Presentational immediacy, on the other hand, is singularly indifferent to past and future alike. It concerns itself with the present world - the world contemporaneous with the percipient. However, as advances in relativity physics have shown, "the present" is a term with as many meanings as there are "presencing" occasions. The only possible universal meaning of contemporaneity is causal independence. For Whitehead, occasions are contemporaries when they do not enter into each other's constitutions, when they do not physically prehend each other. Thus, every occasion enjoys its drop of experience alone. This is not to say, however, that "nothing is going on" in the world contemporaneous with a concrescent occasion. This world is a multiplicity of self-actualizing activities, each involved in creating its own drop of private enjoyment. The past is populated with factual occasions of experience; the present, with potential, "about-tobe" occasions. Therefore, the past is incurably particulate; the present, only potentially divisible: a continuum of possible perspectives yet to be specified. Both are extensive, but in different ways. The past is a network of concrete, interlocked, spatio-temporal facts-the extensive continuum as atomized by mutually implicated, satisfied occasions. The present, as not yet atomized, is the extensive continuum considered as the abstract schema of possible extensive relations which could be atomized. In other words, the present is the pure unbroken continuitypossibility of spatio-temporal extensity. When a concrescence objectifies its present, it does so as a locus of possible relations, as a continuum of interlocked, possible perspectives-as a continuous, spatio-temporal region.

\footnotetext{
${ }^{20}$ Inasmuch as symbolic reference, the taking of one modality of perception as symbol of the other, is a proto-judgment.
} 
Whereas in causal objectification the eternal objects involved are the sensa (the vector feeling-tones of past agencies), in presentational objectification the eternal objects are those pertinent to spatio-temporal, extensive relations. An occasion for which the present is significantthat is, an occasion which achieves novel immediacy in its satisfaction, which appropriates its past for itself in a personal "now" which is important to it rather than merely passing along that past to the futurespatio-temporalizes its world, displaying its present as a continuum of spatial and temporal relations, thus lifting the past into its present. For vaguely social occasions, such as those constituting a physical field in empty space, subjective immediacy and intensity do not have any relevant import; hence "no intelligible definition of rest and motion is possible for historic routes including them, because they correspond to no inherent spatialization of the actual world" (PR 177). They are victims of the geometry of whatever societies with significant presented duration happen to wander through them. Thus, the sun can alter the structure of its environing space, as evidenced in the bending of light waves which pass close to it. Geometries are relative to the mode of spatialization important to varying societies. Hence, no one geometry can be absolutized. The extensive continuum is not geometric in the strict sense of the term, but merely the schema of possible extensive relations of the most general sort, those of "extensive connection," "overlapping," etc., described in Part IV of PR.

What is felt via the spatio-temporal eternal objects accomplishing presentational objectifications is the past as present to the concrescent occasion, as enjoyed in the present of its drop of experience. Presentational objectification is therefore found only in those occasions whose environment and subjective aim promote the subjective enjoyment of experience, occasions for which the "now" is important.

In perception in the mode of presentational immediacy, something more than mere presentational objectification is taking place. It is not simply the case that the conscious occasion is displaying the past in its present; it is further interpreting that display as a display of the contemporaneous world: of "a contemporary spatial region, in respect to its spatial shape and its spatial perspective from the percipient" (PR 121). But pure extensity cannot be displayed in itself. A circle is given in the equation $x^{2}+y^{2}=r^{2}$, but the equation does not display circularity unless it is plotted on a set of coordinates in ink of a determinate color. The visual sensum allows the circular shape to be seen. Extensity must be "decorated" with sense data before it can enter into conscious perceptual experience. The so-called secondary qualities illustrate (make visible, audible, etc.) the extensity of the contemporaneous world, allowing 
the stone, for instance, to enter into experience as a gray shape contemporaneous with the perceiver.

An adequate theory of presentational immediacy must therefore give an account of the two sets of eternal objects through which the objectification of the contemporaneous world takes place. One set-the spatiotemporal eternal objects-is contributed by the region perceived from the standpoint of the perceiver; the other set-the perceptual qualities-is contributed by the historic route through the animal body, as it enters into the composition of the percipient occasion. Both sets are universal, abstract eternal objects functioning as relational between perceiver and perceived. Both lack the insistent particularity and causal relevance of the past region which they represent. In one sense, therefore, perception is the entertainment of universals, but they do not float into consciousness from nowhere. The extensive set have their origin in what Whitehead calls "strain feelings"-complex physical feelings of the geometric relations latent in the datum ${ }^{21}$ and given for the concrescence. The qualitative set is given by the past functionings of the animal body and is "an adventitious show, a show of our own bodily production" (S 44), conceptual reversions resultant from the physiological imbalance caused by the strain feelings. Thus the bodily produced percepta exhibit the contemporary environment as an extensive set of important regions systematically related to each other and to the percipient $^{22}$ and shading off into extensive backgrounds of less and less importance.

As opposed to the indistinctness of causal efficacy, the display produced in presentational immediacy is a vivid and geometrically precise rendering of the manageable elements in experience, a show which is totally barren as far as meaningfulness to the perceiver is concerned. It reveals nothing about the "thing" perceived, not its past or its importance to the perceiver and for the relevant future, or its causal relations to other "things" and to the percipient. Hume was quite correct: pure impressions merely come and go, succeeding each other without any genuine internal connection. Presentational immediacy is total absorption in the "now." "The present moment is then all in all" (S 42): a total, self-contained solipsism. The value of presentational immediacy lies in the fact that its vivid display of the contemporaneous world in no way violates the mutual independence of contemporary occasions. It reveals the present solely in its potentialities: as a systematic locus and a presented duration undergirding the extensive togetherness of

${ }^{21}$ These are discussed at length in Chapter 6.

22 "Focal regions" and "seats," in the language of Part IV of PR. 
possible occasions arising within it. ${ }^{23}$ It is perceived in quasi-independence of those actualities growing within it-as a mirror image illustrates the space "behind" the mirror. But the presented locus is not in complete independence of actuality. It bears a perfectly definite, systematic, geometric relatedness to the body of the percipient, which relatedness is definable in terms of straight lines. ${ }^{24}$ This fact necessitates, however, that the traditional understanding of straight lines in terms of events ${ }^{25}$ be replaced by more fundamental and purely formal definitions. ${ }^{26}$ The presented locus likewise bears a relation to past societies in the region, a relation which can be explicated only in the context of the integration of presentational immediacy and causal efficacy which Whitehead calls "symbolic reference": the ordinary form of human sensory awareness.

\section{c. Perception in the Mode of Symbolic Reference}

For Whitehead, the "human mind is functioning symbolically when some components of its experience elicit consciousness, beliefs, emotions, and usages, respecting other components of its experience. The former set of components are the 'symbols,' and the latter set constitute the 'meaning' of the symbols" (S 7-8). The ability to make the transference from symbol to meaning is not necessarily a high-grade activity proper to man alone. Blind transference-symbolically conditioned action-characterizes all vertebrates, certainly the more complex invertebrates, and perhaps all life forms as well. The tendency to take the present as a symbol of a past agency which can lead to the future weal or woe of the organism appears to be one of the indicators of the presence of life. To be more precise, the specifically human capacity seems to be the ability to inhibit the transference: to remain on the level of the symbol (e.g., the artist, the geometer, the algebraist, the lexicographer, etc.). Very young children (and primitives as well) appear to have difficulty with pure symbols. They want them to stand for some thing, not an irrelevant unknown.

The symbol-to-meaning transfer is not to be interpreted as an activity

${ }^{23}$ To make this discussion a bit more concrete: what Whitehead is saying is that the white rectangular area one sees when looking at this page - an area which is an unbroken continuum as far as the visual image is concerned-is a region within which entities are concrescing and which they will atomize into discrete facts when they have reached satisfaction. It is where actual entities will be, not where they are.

${ }^{24}$ The lines utilized in the construction of a perspective in art are instances of this relatedness.

${ }^{25}$ E.g., the shortest distance between two points; the path of an unimpeded moving body.

${ }^{26}$ This is part of the purpose of Part IV of PR. 
performed by an already constituted entity. It is an element in the constitution of the percipient occasion, a synthesis of earlier prehensions in its self-creative process. By means of the synthesis, the percipient defines its actual world, vividly delineating features in its immediate past which have import for its future. The colored shapes, the sounding, odor-full spaces represent other, more primitive elements in its experience, toward which its future behavior must be adapted. The symbols do not, therefore, create the physical bodies in the external environment which they represent; they discover them as already having been causally felt in earlier phases of its self-production. By means of the transfer, the colored shapes, etc. which are projected in the continuum of extensity of the present are taken to be indications of genuine causal presences in the regions into which the sensa are projected. Past agency is extrapolated as emerging agency in the present.

This transfer is a learned response: "nature taught [its] use" (S 57) through the pragmatic interactions of enduring, living organisms and their environment. Furthermore, which environmental influences are presentationally objectified is likewise pragmatically determined. ${ }^{27}$

Since symbolic reference is a learned response, it is fallible. In fact it is only with respect to symbolic reference that truth talk has any relevance. The other perceptual modes are infallible: causal efficacy, because it is the constitution of a percipient arising from the causal influx of its past; presentational immediacy, in that the display simply is what it is-a gray shape, a sour taste, a flowery odor. Truth and error come about in the synthetic activity referring the shape, the taste, the smell to an environmental agency. Human perception, therefore, is a complex inference, a "judgment," which can go wrong for lack of experience or as a result of pathological conditions within the organism. Symbolic reference "may induce actions, feelings, emotions, and beliefs about things which are mere notions" (S 6), i.e., which are not exemplified in the actual world of the concrescence.

To identify symbolic reference as the seat of error is neither to downgrade the activity nor to make error seem a cardinal sin to be avoided at all cost. One function of reason-a subsequent refinement introduced by high-grade occasions - is to pass judgment on the blind transferences which take place earlier in the concrescence, thereby purging them of possibly erroneous meanings.

The "evolutionary use of intelligence is that it enables the individual to profit by error without being slaughtered by it" (PR 168). Error is

\footnotetext{
${ }^{27}$ See Bergson's theory, as expressed in Matter and Memory and Creative Evolution, that perception consists in the tracing in advance of an organism's potential action in and on the environment.
} 
not therefore to be construed as a totally destructive agency. Rather, it promotes imaginative freedom, a liberation from the given which enables mind to soar into realms not exemplified in the concrete. As Whitehead succinctly puts it, "in the real world it is more important that a proposition be interesting [i.e., opening up novel vistas] than that it be true [conforming to the given actual world]" (PR 259). The halfsubmerged stick which appears bent, the apparent lowering of the pitch of a sound emitted by a moving object, the reflection which deceived Narcissus-all are erroneous transferences which opened up new areas of truth. The entire human mythopoetic faculty, in its creation of art, religion, literature, music, etc., reveals in its "errors" a world of possibilities not exemplified in actual fact, and frees man from slavery to the concrete. But even prior to the activities of both critical reason and deliberate myth-making, symbolic reference is purged of its more blatant mistakes through interplay with the environment, in the dialectic between symbol use and its pragmatic consequences.

If, however, there is to be any validity whatever to symbolic transfers, there must be some ontological ground to symbolic reference, some objective communality between meaning and symbol which provokes the synthesis, which makes the diverse elements apt for synthesis. This communality cannot be of the sort which would intrinsically specify which components can be symbols and which can be meanings without at the same time bifurcating reality into experienced things $v s$. things unexperienced, thought things $v s$. things as unthought: the dilemma bequeathed by the history of philosophy from Descartes to Hume, which compelled Kant to divorce phenomena from noumena irrevocably. For Whitehead there can be neither pure symbols nor pure meanings; which component of experience (causal efficacy or presentational immediacy) assumes each role is decided in the concrescence: "symbolic reference holds between two components in a complex experience, each intrinsically capable of direct recognition" (S 10; emphasis added). Nor can the communality making transference possible guarantee that it will be free from error. As in any judgment-any synthetic activity conjoining elements given as separate or separable-the percipient assumes "moral responsibility" for the truth of perceptual inferences, maintaining a watchfulness for physiological or environmental abnormalities which might so distort appearances that their reference to reality is unjustified.

That which is common to both perceptual modes is a twofold set of structures directly recognizable as identical in both: a set of eternal objects with a two-way functioning. The first of these is the set of sensa given for presentational immediacy as derived from the actual world of the conscious percipient: from the functioning of the sense organs in the immediate past, not directly from the perceived object. By means 
of these eternal objects, the organ region is objectified (via a transmuted feeling) as the contributor of the sense data. ${ }^{28}$ The "sense-data functioning in an act of experience demonstrate that they are given by the causal efficacy of actual bodily organs" (S 51). The implications of this statement need careful clarification. Our language is too steeped in Aristotelian categories for Whitehead's notion of a sensum to be grasped readily. Quality words are adjectives-states of either objects or subjects ${ }^{29}$ - which accidentally modify objects or subjects. In an Indo-European language, "blue" invariably ends up qualifying a noun (the "name of a person, place, or thing"); in Whitehead's conception, it is the subjective form of a relational activity: a vector feeling-tone not a bare passive quality, an adverb not an adjective. "Blue" cannot be abstracted from the eye's functioning in response to an environmental stimulus; it has no meaning apart from an eye. It is the eye's activity of grasping into itself the causality of a light wave objectified by an item in the wave's definiteness: its energy structure or frequency. The illustration is, of course, oversimplified. A more correct physiological account would include several intermediate objectifications between the eye and the percipient occasion. The frequency of the light wave is objectified by the rods and cones in the retina as a determinate bleaching of their included pigments. This bleaching itself is objectified as a burst of electrical energy of a certain frequency, which is transmitted via the central nervous system to the visual cortex in the brain, where further objectifications eventually lead up to the blue-experience. All these different yet related objectifications are accomplished by conceptual reversions in the route. The causality of the light wave, and, for that matter, the causality of the environmental object reflecting it, are thus transmitted through the route by means of the reverted sensa. Because of the reversions, the sensum-as-experienced - the structure the causality ultimately assumes - is contributed by the bodily occasions in the route; but, despite the reversions, the ultimate objectification to the percipient occasion retains the vector feeling-tone of its origination in the eye region: a feeling of the sensum as impressed on the eye.

In presentational immediacy, the sensa given by the bodily route and felt in the conformal and aesthetic phases of the percipient's concrescence are projected on a contemporaneous region, thus objectifying and illustrating its extensity via sense qualities. The conscious-awarenessof-a-blue-area - the sense impression-is the last link in this chain of objectifications. Hume is totally wrong. The causes of impressions are known.

\footnotetext{
${ }^{28}$ Even a dog experiences the fact that he smells odors with his nose.

${ }^{29}$ Depending on where one is a sensationalist or a subjectivist. See PR 157.
} 
If Hume had stopped to investigate the alternative causes for the occurrence of visual sensations-for example, eye-sight, or excessive consumption of alcohol-he might have hesitated in his profession of ignorance. If the causes be indeed unknown, it is absurd to bother about eye-sight and intoxication. The reason for the existence of oculists and prohibitionists is that various causes are known [PR 171].

Be it genuine external stimulation, myopia or martinis, the functioning of the eye is the cause of the blue-seeing experience.

In presentational immediacy, diverse regions are illustrated and objectified: the object region and the eye region; but at the same time there is an identity of sensa involved. The sensa contributed by one region (the past functioning eye) are used to illustrate the contemporary object region. The eye region is causally objectified by the vector feeling-tone, "blue-seeing," which eternal object, stripped of its vector origin, and enhanced, is projected on the contemporary object region. The contemporary eye region is presentationally objectified as well, via a different yet related eternal object-the feeling-of-functioning: "eye strain" as a conscious phenomenon projected on the eye region to illustrate it more precisely. This double objectification of the eye as both past and present serves to identify further and to locate more precisely the cause of the given sensum.

Therefore, as a result of the same sensum felt as characterizing the past activity of the eye region in causal efficacy and hence projected into the contemporary object region in presentational immediacy, the symbolic reference can take place. The two prehensions can be synthesized into a unity of feeling, the feeling of a contemporary blue wall in the external environment. Yet the two-way functioning of the sensum is not sufficient fully to ground symbolic reference, for there remains a diversity of regions involved: $(a)$ the past object region which was the vector origin of the causality received by the eye, and the eye as the vector origin of the transmitted sense; and $(b)$ the contemporary object and organ regions as presentationally objectified. If the illustration of (b) by sense derived from $(a)$ is to be legitimate, there must be some felt communality between the two sets of regions.

One fairly obvious intersect of past and present is the human body presentationally objectified as the geometric focus of both external and internal regions.

... the animal body is the great central ground underlying all symbolic reference. In respect to bodily perceptions the two modes achieve the maximum of symbolic reference, and pool their feelings referent to identical regions. Every statement about the geometrical relationships of physical bodies in the world is ultimately referable to certain definite human bodies as origins of reference [PR 170]. 
... the spatial and temporal relationships of the human body, as causally apprehended, to the external contemporary world, as immediately presented, afford a fairly definite scheme of spatial and temporal reference whereby we test the symbolic use of sense-projection for the determination of the position of bodies controlling the course of nature [S 56]. ${ }^{30}$

The centrality of the human body in the perceptual field is not sufficient, however, to ground metaphysically the projection of data from a past "place" onto a present "place," for the two "places" are ontologically different in character. The vector origin of the sensa-proximally the bodily region and ultimately the environmental region-is the incurably atomic, factual plenum of discrete, satisfied occasions of the immediate or more remote past. It is the extensive continuum as ruptured by actualization. The contemporary place is the extensive continuum as unruptured, as divisible yet undivided-pure extensity considered as the locus of possible relations of future occasions. It is a "duration" in the spatio-temporal sense of the term detailed in SMW, the extended present in its potentiality for subdivision. If symbolic reference is to be legitimate, this presented locus must also be felt in the earlier causal feelings. It cannot be directly felt, for this would violate the causal independence of contemporary occasions. However, it is felt indirectly and objectified vaguely in causal feelings of the antecedent world. Although each occasion contemporaneous with the percipient occasion is "alone" in its enjoyment of its own unique actual world, those actual worlds are practically identical as far as their important elements are concerned. Social occasions share an almost common world, with an almost common real potentiality. Therefore, in the percipient's causal feelings of its own actual world, of its own real potentiality, it is simultaneously grasping the important aspects of the real potentiality given for its contemporaries. In grasping the causal influx to which it is subject, it grasps at the same time the important causal past of its neighbors concrescing in the present. It is therefore physically feeling the presented locus indirectly, by extrapolation. This feeling is vaguely defined in causal efficacy as $(a)$ feeling of the "aroundness" of the environment-an "aroundness" incapable of more precise elucidation - and of the vague "thereness" of contemporary oc-

\footnotetext{
${ }^{30}$ This point was underlined in a set of experiments in which subjects were fitted with lenses that inverted the visual image projected on the retina, making everything appear upside down. When allowed to move through their environment, using their kinesthetic and factual senses, the topsy-turviness of the environment soon disappeared. The pragmatic check on the illusion by the other senses caused it to disappear, despite the fact that the physical cause remained (Irvin Rock and Charles S. Harris, "Vision and Touch," Scientific American, 216, No. 5 [May 1967], 96-104).
} 
casions; and (b) the "withness" of the contemporaneous body, whose geometry is felt with a bit more precision because of the greater shared importance and degree of coordination of the data. Causal efficacy gives, therefore, a vague sense of important contemporary regions with, however, no clear-cut geometrical relations and structure.

When presentational feelings grow out of these indirect causal feelings of the presented locus, it is then directly felt: that is, the presentational feelings are feelings of the causal feelings as objectified by an aspect of themselves-the vague feeling of the presented locus. The subjective forms of these presentational feelings are the precisely and vividly displayed geometric eternal objects of presentational immediacy. These are directly illustrated instead of vaguely felt, and constitute the display of the contemporaneous world, a geometry decorated with sense data. "Thus the presented locus, with the animal body of the percipient as the region from which perspectives are focussed, is the regional origin by reference to which in this perceptive mode the complete scheme of extensive regions is rendered determinate" (PR 169).

The past world, directly objectified in causal efficacy, gains only indirect objectification in presentational feelings, an objectification grounded in its extensive relations to the presented locus. Pure presentational immediacy yields, therefore, a pure phenomenology of appearances with existence bracketed, "direct observation ... purged of all interpretation" (PR 169). It illustrates the set of geometrical relations unexplicated in indirect causal feelings of the presented locus-of the regions in the body, of regions to the body, of regions to other regions from the perspectival standpoint of the body, and of the systematic divisibility of all regions. The presented locus, as indirectly prehended in causal efficacy and directly grasped in presentational immediacy, undergirds symbolic reference and permits past sensa to be projected on a present world, as a vision of "what the nexus really is in the way of potentiality realized" (PR 269).

In the doctrine of symbolic reference, Whitehead gives his definitive critique of Hume and Kant, demonstrating their position to be an inversion of experience. He sees them as asserting that perception is the most concrete element in experience, and that causality is either an $a$ priori form of the perceiver or an unwarranted inference from perceptual data. Both are therefore maintaining the primacy of presentational immediacy as the only source of information about the present world, a source which reveals no ties to past or future. It was quite logical for them to infer, therefore, that causality was either a category of pure reason or a mere invariable sequence among impressions, one "learned" through habit. If their doctrines are correct, however, to dim perception would be likewise to dim causal feelings; whereas precisely the reverse occurs. 
Whitehead takes the position that causal feelings are primary, being the basic physical, conformal feelings out of which the percipient constitutes itself, ${ }^{31}$ that such feelings characterize even the most primitive occasions, and that presentational feelings are derivative. Occasions can be separated into four categories on the basis of the importance of presentational feelings in their satisfactions: (a) those with minimal presentational feelings because the order in their environment is so trivial that their common world is virtually non-existent, thus rendering whatever vague feelings they have of the presented locus almost absolutely irrelevant (hence such occasions do not spatialize their present); (b) occasions for which presented durations are important but not clearly discriminated into regions (occasions in personal threads in inorganic societies, for example); (c) living occasions for which the present is vitally important and which hence enhance presentational feelings and perform symbolic references, thus making possible self-preservative activity; and $(d)$ human percipients, who can transcend the necessity of presentational display of the actual past, imaginatively display what is unexemplified in the world, reorganize the given, adjust given values, and critically judge their own operations. Humans can likewise expand symbol use beyond the limits of perception, in language, art, science, mathematics, social custom, etc., enabling them not only to live and live well, but to live better (see FR 8).

\section{V • Prolegomenon to A Theory of Judgment: Propositions}

The epistemological difficulties besetting modern philosophy were not restricted to those directly connected with misconceptions of the nature of perception. They pervaded analyses of the higher modes of human conscious activity as well: specifically the activity of judging, and its truth value. Whitehead's theory of propositions is an attempt on his part to circumvent such problems by grounding his epistemological theories in ontology. Just as sense perception is interpreted as a more complex integration of the primitive feelings initiating a concrescence and not as a feeling radically discontinuous with and ungrounded in earlier feelings, so the act of judging, as an element in the constitution of an act of experience, is seen as a further integration of earlier feelings-in this

${ }^{31}$ "The first phase is the phase of pure reception of the actual world in its guise of objective datum for aesthetic synthesis. In this phase there is the mere reception of the actual world as a multiplicity of private centres of feeling, implicated in a nexus of mutual presupposition. The feelings are felt as belonging to the external centres, and are not absorbed into the private immediacy" (PR 212). 
case, as a "comparison" of a "propositional feeling" and an initial physical feeling. ${ }^{32}$ The former is itself a complex feeling having as its datum a "proposition" ${ }^{33}$ given for it in the definiteness of the data. Since the data and the series of feelings by means of which they are integrated are the act of experience of the judging actual occasion, Whitehead need admit of no ontological bifurcation of nature into experience and things experienced. The former is the togetherness of the latter: "togetherness in experience" is the only type of togetherness in the philosophy of organism.

Since this is the case, the affirmation of the truth or falsity of a proposition (the act of critical judgment) is an affirmation of the togetherness or non-togetherness of elements in the constitution of the judger, which in turn is the togetherness or non-togetherness of the ideal and real worlds from the judger's perspective. An affirmative judgment is not, therefore, the conjugation of a logical subject and predicate given as disjoined; it is the affirmation of a more primordial togetherness in experience, which is togetherness in the actual world the felt synthesis of which is the experient occasion.

The togetherness affirmed or denied in a judgment is the togetherness of an eternal object (the predicate) and an actual entity or nexus of actual entities (the logical subject). This togetherness, as given in the actual world of a concrescence, is what Whitehead terms a proposition. Therefore, propositions not merely are data for logicians to exercise their wits on, but are hybrid entities which are elements in the definiteness of the universe out of which an occasion arises. Furthermore, it must be remembered that no artificial separation exists between a proposition and the feeling of a proposition. Such a separation is an abstraction with no concrete exemplification in the world. There are neither mere concrescent subjects with mere subjective activities, nor mere objects with mere objective propositional characters. To be a proposition is to be a proposition for a concrescent subject (actual or potential) and entertained (or entertainable) by that subject.

Prior to an analysis of the judging activity, it is therefore necessary to examine that peculiar modality of togetherness between actual entities and eternal objects which can be termed propositional. Not every conjunction of actual entities and eternal objects constitutes a proposition. Some are merely the lower grade of prehension which Whitehead calls "physical purposes." These are indeed grasps of the togetherness

\footnotetext{
${ }^{32}$ The genesis of these complex, synthetic feelings will be laid out in Chapter 5 .

33 ".. . Matters of Fact in Potential Determination" (PR 22); ". . . a proposition is the unity of certain actual entities in their potentiality for forming a nexus, with its potential relatedness partially defined by certain eternal objects which have the unity of one complex eternal object" (PR 24).
} 
of a nexus and an eternal object, but the eternal object in question is grasped not in its transcendent character-i.e., as a possibility for any actuality - but merely as a possibility exemplified in this nexus, as "tied to the datum." For example, the appetitive grasp of the "warmth" of a particular fire, the "safety" of one's home, the "thirst-quenching wetness" of this glass of water are physical purposes. The eternal objects are grasped only as exemplified in the fire, the home, the glass of water, not as potentialities for exemplification in other actualities. Furthermore, the grasp is emotive-appetitive: a "desire" for the datum as exemplifying the eternal object. The "could-be $v s$. is," potentiality $v s$. actuality, contrast is missing. Hence, for reasons to be explored later, physical purposes are unconscious elements in the aesthetic supplement of an actual occasion, lacking the affirmation-negation contrast which Whitehead sees as central to consciousness and intellectual supplementation. ${ }^{34}$

In a proposition, it is the "could-be" of the eternal object which is important-the "germaneness of a certain set of eternal objects to a certain set of actual entities" (PR 188; emphasis added). The togetherness of the logical subject and predicate, the nexus and the eternal object, is potential; it is a togetherness proposed as realizable within the concrescent subject, not given as already realized. Whether the eternal object is actually realized in the nexus or not is an additional qualification differentiating true from false propositions, but not an essential characteristic of propositions as such. In either case it is the potential relevance of the eternal object to the nexus--their potential togetherness-which distinguishes a proposition from a physical purpose.

The object of a propositional feeling is this potential togetherness; hence a propositional feeling is a hybrid feeling - one which involves a synthesis of a prior transmuted feeling of the nexus-as-one and a prior conceptual feeling of the eternal object in terms of which the transmuted feeling was possible. To clarify this obscurity by a simplistic example: if the nexus is a society of actual entities each of which inherits and exhibits the defining characteristic "stone," the multiple physical feelings of the members of the society are transmuted into one feeling of the nexus as unified by the defining characteristic "stone." The original feelings are "simplified" in their transmutation into one feeling. The eternal object making the transmuted feeling possible is then felt in a pure conceptual feeling. ${ }^{35}$ The synthesis of these two feelings in one hybrid feeling constitutes the propositional feeling "This

\footnotetext{
${ }^{34}$ See Chapter 5.

${ }^{35}$ The origination of pure conceptual feelings out of physical feelings will be elaborated in the genetic analyses of Chapter 5.
} 
nexus could be a stone." That the eternal object proposed as a predicate relevant to the nexus is exemplified in it as well is the additional qualification rendering the proposition true.

If the proposition is false-i.e., if the proposed predicate is not realized in the nexus physically felt-the unexemplified eternal object does not float into subjective experience from nowhere. Rather, the concrescent subject performs a conceptual reversion upon the eternal object felt as actually exemplified in the nexus, a reversion grasping another eternal object related to that structuring the nexus as a relevant and alternative way in which that nexus could be realized as an element in the constitution of the emerging subject. In the preceding example, the pure conceptual feeling of "stone" - the eternal object both exemplified in and possible for the nexus-could be reverted to "weapon," an eternal object relevant to "stone" but not exemplified in the stone society, and the reversion integrated with the nexus feeling as "This could be a weapon." ${ }^{36}$ False propositions are thus the lure for novelty in the world. Without their possibility, the present could only endlessly re-echo the forms realized in the past.

Just as a propositional feeling is a hybrid prehension, a proposition is a hybrid entity in the actual world for the propositional feeler. It is the togetherness of a nexus and the penumbra of possibility which surrounds its factuality. It quite literally takes the "S is P" form: the subject being the actual entities in the nexus; the predicate being the eternal object, the complex pattern, in terms of which the factual entities could be structured for the concrescent occasion. In Whitehead's words, a proposition is "particular facts in a potential pattern" (PR 194), the particularity resulting from the past satisfactions in the nexus, the potentiality from the relevance of eternal objects to the nexus from the perspective of the propositional feeler.

Propositions are not given to an occasion primarily for purposes of judgment; they are proposed as "lures for feeling": as possible values to be entertained, not to be judged as to past exemplification. They offer themselves for intrasubjective realization, for a private enjoyment which may be followed by critical evaluation but need not be. Propositions therefore initiate feelings which can transcend the givenness of the past and open the door to novel futures. In more complex feelings, when the "S could be P" of the proposition and the "S is objectified by P" of the basal physical feelings are felt together in the affirmationnegation contrast, consciousness arises as the subjective form of the

\footnotetext{
${ }^{36}$ The reader is urged to take the examples solely as aids to understanding, not as explications of conscious, judgmental processes.
} 
synthetic feelings. It is to be noted that the contrast relates the actual and the potential exemplification of the eternal object in the nexus, a contrast absent from physical purposes, which concern only the eternal object as embodied.

In still more complex feelings, the " $\mathrm{S}$ could be $\mathrm{P}$ " is grasped as a genuine novelty because of its contrast with the non-exemplification of $\mathrm{P}$ in the nexus. With such feelings, arising from the entertainment of false propositions (the togetherness of a nexus and predicates possible for it but not exemplified in it), novelty enters the world: novel individuals, new facts, genuine creativity as opposed to merely more complex and hence "new" modes of feeling. The "interesting" proposition has infinitely more evolutionary worth than the merely true proposition.

This description of a proposition as the potentiality of a nexus makes more concrete the discussions of the primordial nature of God which have preceded, for the reason why certain patterns are relevant to a nexus whether or not that nexus factually exemplifies them lies in the protean ordering of eternal objects on which finite process depends. Without an order among eternal objects which is independent of the relevance imposed by joint exemplification, novel advance would be impossible, and process would be an endless re-enactment of the past-a symphony embodying one chord and its inversions. Given the togetherness of the divine ordering and the world of fact, a togetherness manifested in propositions, finite process is drawn forward on the road to novelty. The divine ordering, logically expressed, is the "if $p$, then $q, r, s, t, \ldots$. which enables a reverted feeling to grasp $t$ when only $p$ is given.

The propositions in the world "grow" with the advance of the world. Some are already "in" the world, in the actual entities "whose actual worlds include the logical subjects" (PR 186): others are not realized as yet for any actual occasion or in any actual world. These latter are the unrealized potentials of the universe, "await[ing their] logical subjects" (PR 188), pure, abstract hypotheses as yet ungrasped and ungraspable.

If a proposition is to be felt as "particular facts in a potential pattern" (PR 194), these facts must be stripped of their own pattern-of the objectification by which they were physically felt at the inception of the concrescence-in order to be integrable in the potential predicative pattern. The subjects of a proposition, though fully definite actual occasions, do not bring their full determinateness into the predicative relation. In a proposition they function as bare relata, variables whose relations are those assigned to them by the predicate. As such, they can only be indicated in the proposition, and can have no character of their own. (Whitehead is ontologizing what is a common property of subjects 
of logical propositions: i.e., that in the context of the proposition, they have no intelligibility other than that assigned them by the predicate.) Indeed, the propositional subjects must be indicated if the scope of the proposition is to be made determinate. Hence, quantifiers in logic serve to restrict the locus of the predicate to just these members, be they particulars, kinds of particulars, or kinds of sets.

Whitehead sees two modes of "ontological" indicators: $(a)$ a simple variety-position indicators such as "this," "here," "now," "that," "there," "then," etc., functioning in propositions like "this set of actual entities (the S's) could be a chair (P)"; and (b) more complex indicators such as the italicized in "John bought the tickets from Jim for $\$ 10$," which point to the sets of actual entities involved in the "bought-fromfor" relational pattern. ${ }^{37}$

The former are the ontological, spatio-temporal indicators which are verbally symbolized in demonstrative pronouns and their correlatively implied positional adjectives. Such indicators cannot function, however, unless they are enmeshed in an overarching indicative system; otherwise the absolute, isolated, barren abstractness of "here," "now," "there," "then" as described in Hegel's Phenomenology destroys any possibility of synthesizing the subjects via the predicate. This indicative system is an eternal object of the order of a general principle-a complex eternal object exemplified through instances of itself which are eternal objects themselves. ${ }^{38}$ The instances necessarily embody the general principle, but the realization of the general merely necessitates an instantiation, not which instantiation. (In fact, the various instances of a general principle are mutually exclusive.) The indicative system unifying individual indicators is such that it concerns itself solely with direct unmediated and hence dyadic relations between pairs of propositional subjects ${ }^{39}$ related by the eternal objects which are its instances. An example of the simplest variety of this type of indicative system is the directional system of compass coordinates, whose instances are the eternal objects "east of," "west of," "north of," "south of." Let us consider an actual entity, $\mathrm{X}$, whose actual world is defined by the actual entities A, B, C, and D. From the standpoint of A, the following dual relations hold: $B$ is north of $A, C$ is east of $A, D$ is south of $A$. From these relations it follows that $B$ is northwest of $C$ and that $D$ is southwest of $\mathrm{C}$. From the standpoint of $\mathrm{X}$, if $\mathrm{X}$ feels its relation to A (as west

\footnotetext{
${ }^{37}$ In both examples, it is the ontological state of affairs which constitutes the proposition and its indicators, not the verbal expression.

${ }^{38}$ Thus, "triangle" is a general principle, having scalene, isosceles, equilateral, etc., as its instances.

${ }^{39}$ Note that, as Charles Sanders Peirce points out, all spatial and mechanical relations are dual, involving pairs of particles (Collected Papers, edd. Hartshorne and Weiss, 1.325, 1.457).
} 


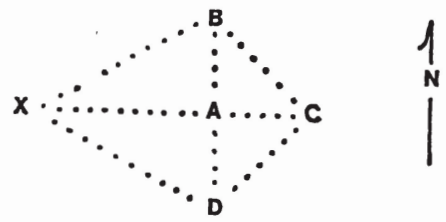

of A) and feels A's relations to B, C, and D (which in feeling A it must also feel, because $A$ is its relations to $B, C$, and $D$ ), then $X$ likewise feels its own relations to $\mathrm{B}, \mathrm{C}$, and $\mathrm{D}$, and all the interrelations of $\mathrm{B}, \mathrm{C}$, and D. The system - the general principle of "compass relationship"makes it possible to indicate the position of each member from the standpoint of any other. In other words, this is an objective indicative system, one not dependent on the idiosyncratic characters of the perspectives realizing it. The experient can be eliminated, while the system still stands. This type of system permits the precise "location" of the subjects of a proposition with respect to each other so that as thus indicated and mutually coordinated they can be enmeshed as variables in the predicative pattern.

Indicative systems not specifying dual relations are less precise in their indication of the propositional subjects. They are vague in the nexus itself, being rendered determinate by the perspective of the experient occasion. In Whitehead's example, the proposition "Caesar has crossed the Rubicon," 40 what is indicated by "Caesar" and "Rubicon" depends on whether the experient is a legionnaire in Caesar's company or a present-day historian, being a function of the direct perceptual experience of the experient. For the legionnaire, Caesar is an historic route of experienced Caesarian occasions culminating in the experienced $\mathrm{Ru}-$ bicon-crossing, and the Rubicon is the perceived river. For the historian who has never seen the Rubicon, both it and "Caesar" denote types of nexuses, not actual nexuses. The legionnaire affirms a particular proposition; the historian, a general one. It is obvious therefore that between the propositions asserted by the legionnaire and the historian there lies a continuum of other propositions all assuming the same verbal form but whose "objective content" as denoted by the "Caesar" and "Rubicon" indicators is quite diverse. Hence, though position indicators may supply an objective spatio-temporal reference system, beyond that, any proposition has indeterminations to be rendered determinate by the functioning of the prehending subject from its relativistic perspective. No verbal statement can completely exhaust the possibilities of a proposition because of this inherent indefiniteness. A proposition is "the po-

${ }^{40}$ Again, the state of affairs, not the verbal expression. 
tentiality of the objectification of certain presupposed actual entities via certain qualities and relations, the objectification being for some unspecified subject for which the presupposition has meaning in direct experience" (PR 196-97; emphasis added). The actual objectification solves the indeterminancy, because the specification of the feeler, and consequently of its actual world, determines what will be the real "meaning" of the proposition for this feeler. The indicators may point to the logical subjects of the proposition, but the perspective of the emergent feeler ultimately decides what they are for it. Thus, "Caesar has crossed the Rubicon," as the potentiality for objectifying Caesar and the Rubicon via the relation "has crossed," means (when taken in abstraction from a concrete feeling subject) "a Caesarian type of route has crossed a Rubiconian type of route," in which expression the Caesarian route is located in the Roman world of 49 в.c. and the Rubiconian route, in Italy. How the potentialities of "Caesarian" and "Rubiconian" are further specified is a function of the actual world of the experients entertaining the proposition: of the legionnaire or of the historian. Their past experience has determined the objectifications under which both routes have entered into their self-constitutive process. Therefore, as additional indicators, "Caesar" and "Rubicon" are vague and indeterminate.

A proposition thus has both the particularity of actuality in its indication of the actual logical subjects to be conjoined in the predicative pattern, and the generality of possibility in its general reference to indeterminate experients.

A proposition becomes metaphysical when its predicative pattern is capable of relating all possible actual entities as its logical subjects and is in the actual world of all experients. As such, any true proposition of the requisite generality is metaphysical; in addition, any fully general false proposition is metaphysical if and only if it is not only false in itself, but false in any possible specification of itself to particular circumstances.

\section{VI • THE TheORY OF JUdGMENT}

Although the illustrations in the previous discussions have been cast in the structure of the logical judgment, it must be borne in mind that "judgment" is one of the rarer ways in which a proposition is admitted into feeling. The same must be said of the conscious grasp of propositions. Both are more advanced integrations of propositional feelings and earlier feelings arising in a concrescence. The more common subjective forms whereby a proposition is realized in an experient is "entertainment": appropriation via emotional or purposive subjective forms. Thus 
propositions function in the actual world of any concrescence, given that the actual world, and hence the resultant occasion, have the minimum of order necessary to make originative, non-conformal response possible.

As already seen, a propositional feeling is the actual enjoyment of a proposition - the actual integration in feeling of the subjects and predicate proffered as integrable. The judgment is a further integration-a feeling together of a propositional feeling and an earlier physical feeling. In Whitehead's words, it is "a synthetic feeling, embracing two subordinate feelings in one unity of feeling" (PR 193). Judging is the integration of the " $S$ could be $P$ " of the proposition and the " $S$ as objectified (or not objectified) by P" of the basic conformal feeling in which the $\mathrm{S}$ nexus is grasped. It is the togetherness or non-togetherness, the consistency or inconsistency, of two elements in the self-formative experience of the judger which is the "object" of judgment: whether the propositional and physical feelings correspond and cohere. Judgment thus evaluates a proposition with respect to its relevance in the constitution of the judger, enhancing or playing down its role. If propositions are lures for feeling, judgments are the critics of their allurement.

Since judgments concern themselves with "real fact[s] in the constitution of the judging subject" (PR 191), truth talk, with its implications of objectivity, is entirely inappropriate with respect to judgments. They may be correct, incorrect, or suspended in their affirmation of facts in the judger's constitution, but never true or false, since the primary content of the affirmation does not deal with what the universe is in independence of the act of judging. Only propositions are given for a concrescence and hence can be true or false. The judgment remains entirely within the realm of appearances, and can be criticized only by subsequent occasions.

The overt "S is $\mathrm{P}$ " declaration of a state of affairs in the objective world is not, therefore, the primal affirmation of a judgment but one derivative from it by an abstraction which separates $S$ and $P$ from $S$-asfelt and P-as-felt and their propositionally felt togetherness. It is this derivative affirmation - the affirmation of the truth value of the propositional feeling - which is subject to error, for it is an affirmation made in abstraction from the constitution of the judging subject. Hence, there are in fact two modalities of judgment: $(a)$ the intuitive affirmation of appearances; and $(b)$ the affirmation of an objective, external state of affairs derived from ( $a$ ) by a further comparison and integration of feelings. In the intuitive judgment, the full detail of the felt propositionthe totality of the relational pattern-is felt in its contrast with the nexus-as-felt. Such a judgment is the "consciousness of what is" in the full awareness of what it could-be-and-is, and could-be-and-is-not. It is experience compelled to affirm itself, the judgment of consciousness 
affirming its content. Since the intuitive judgment is a "summing up" of the concrescence, it is always correct.

Error enters with the derivative judgment, since it abstracts from the full detail of the proposition and of the nexus, dealing only with aspects of that totality. Thus, "the wall is green" indeed compares the felt possibility of being-a-wall and being-green with a segment of physical experience, but it eliminates the totality of other relations and causal influences (e.g., green lights in the room) which might make the wall appear green. The judgment of appearances is categorical and correct; the judgment of reality is hypothetical and possibly incorrect, and must be validated pragmatically through further experience.

Thus, derivative judgments can attain only degrees of probabilitynever truth or falsity. However, to speak of probability opens the door to the problems with probability theory to which Whitehead had become sensitized by his earlier immersion in the philosophy of science. The difficulty, as elaborated in layman's terms, takes the form illustrated in the following example. If the question is to determine the relative proportion of red and green marbles in a container, and a rubric forbids emptying the container out so that the marbles can be counted, the only recourse possible is the sampling technique. The red-green proportion as evidenced in each of a number of samples will eventually cluster around a mean-e.g., 3:5. We can therefore make the statement that the red-green proportion is probably 3 to 5 . However, is this statement of probability (or the derived statement that the probability of any drawn marble's being red is $3 / 8$ ) certainly true or only probably true? Naturally, the latter is the correct alternative, and the probability of truth of the statement of probability is a function of how randomly the samples were taken, the number of samples, etc. But the validity of the sampling technique itself is grounded in statistical probabilities. To escape the infinite regress which opens up, some non-statistical, non-probabilistic ground must be found to undergird probability statements, a ground neither needing further grounding nor asserting itself as an arbitrary ultimate. In its broadest form, the basic question is of the truth value of human judgment; in its restricted form, of the ultimate justification of induction and of the intuition of probability. ${ }^{41}$

With this simplified version of the problem as backdrop, Whitehead's exposition can be more meaningful. As he sees it, if probability is the proportion of favorable to unfavorable cases in the set chosen as the ground, the question as to why the ground set was selected immediately arises. If the response is that this ground is probably superior to other

\footnotetext{
${ }^{41}$ Note that, as Peirce points out (ibid., 6.476), this "intuition of probability" is also a factor in our selection of hypotheses. Man seems to have an uncanny "sense" for the right hypothesis. Without a sense, science could never advance, given the quasi-infinite plurality of possible hypotheses.
} 
grounds, a second-order probability and the very real possibility of an infinite regress enter. The response must be that the selected ground has an equiprobable character (that it not be a skewed ground) and that this equiprobability must ultimately have a non-probabilistic meaning. For example, in a coin-tossing experiment, the probabilistic ground is the run of throws; but its equiprobable character is grounded in the indifferent two-sidedness of the coin, which ultimately guarantees the probability of any throw (case) turning up a "head" to be one-half.

The necessary finiteness in the statistical ground further complicates the issue, for probability has no meaning in a denumerably infinite set. ${ }^{42}$ The purpose of the sampling technique is to overcome this difficulty, given an infinite ground set. But sampling can do so only if the sampling procedure is absolutely random - purely chaotic and lawless-an impossible rubric. In any sufficiently long run of cases, patterns will appear which result from the minuscule quantum of order latent in the sampling procedure and not from the order sought in the statistical ground. Furthermore, the sampling technique cannot overcome the problem of the novel case (the case not part of the ground) to which the probabilities determined for the ground are to be applied (for example, the extrapolation of the general laws of nature from particular observations). Other evidence is necessary in order to argue from the statistical ground to the novel case, and how is this evidence to be grounded? In fine, must it be the case that science, in its search for the predictable regularities of the universe, must choose between the anti-scientific acceptance of unverifiable probabilities on the one hand and, on the other, the postulation of nebulous "powers" in the things of the world as causative of their regular behavior, an attitude brilliantly burlesqued by Molière in the last intermède to the Malade imaginaire ${ }^{43}$ And in the wider

\footnotetext{
${ }^{42}$ The ratio of heads to throws in an infinitely long run of throws is $\infty: \infty$ or $1: 1-\mathrm{a}$ meaningless probability.

${ }^{43}$ The M.D. candidate is asked:

Si mihi licentiam dat Dominus Praeses

Et tanti docti Doctores

Et assistantes illustres,

Tres scavanti Bacheliero

Quem estimo et honoro

Domando causam et rationem quare and answers: Opium facit dormire

Mihi a docto doctore

Domandatur causam et rationem quare

Opium facit dormire:

A quoi respondeo,

Quia est in eo

Virtus dormitiva,

Cujus est natura

Sensus assoupire.
} 
framework of human judgment in general, must the judger be locked irrevocably in the prison of appearances with no access to statements about reality?

Whitehead's response to both questions is a natural consequence of his theory of actual entities as prehensive unities. Granted: "the data upon which the subject passes judgment are themselves components conditioning the character of the judging subject" (PR 203); nevertheless, the appearances seized in the intuitive judgment are outgrowths of the actual world given for the concrescence, so that the extrapolation from appearance to reality is not entirely without foundation. The togetherness in appearance is the subjective appropriation of the togetherness in a reality of which appearance is a further ordering. The derivative judgment is the final ordering of data given as ordered for the concrescence. Hence the solution to both the objectivity of judgment and the validity of induction lies in the general social character of the region to which the judgment or induction relates.

This social character is given for the judging occasion as an element in the actual world out of which it creates itself, and hence is reflected in its experience and felt in the intuitive judgment. The inductive judgment, since it "has regard to statatistical probabilities inherent in [the] given [social] order" (PR 204), is and can only be the prediction of a particular future on the basis of an observed past, a prediction assuming (a) the environmental stability requisite for the survival of the observed social order, and $(b)$ an analogy between the social order in the environment of the predicted occasion and that in the observed environment. If the future and past societies are to be analogous, the situation can come about only as a result of their having arisen out of analogical data, which can only be given by wider analogous environments. The widest environmental analogies are those provided by the society dominating the cosmic epoch: the so-called "laws of nature." Thus Whitehead is not reduced to postulating either a mechanism of externally imposed law or a crude Aristotelianism of internally determining substantial forms. Regularity is spawned by regularity; ordered environments tend to propagate themselves analogically, because regularity in the past is prehended into present occasions which form the social environment out of which future occasions will grow. (Hence the particularity of inductive judgments.)

The analogy between past and future environments is not to be taken as an identity, however. The social universe is not locked into a wooden order. Societies dominate an environment; they do not totally pervade it. There are chaotic occasions, anarchists, in any society and in any cosmic epoch. Therefore, absolute predictability is impossible. Sampling is necessary, and inductive judgments depend for their probability 
on the size of the set considered and the "amount" of social order observed in it. The primordial sampling and probabilistic judgment is the experience of the judging occasion as it arises out of its actual world and its contained order. Its experience, as intuitively grasped, provides the basis for its vague judgment of "more or less" with respect to favorable and unfavorable occurrence in that actual world, which in turn gives the judging occasion a vague and imprecise intuition "as to the statistical basis of the presupposed environment" (PR 207) from which the future environment can be extrapolated by analogy. There is also an intuition of the "intrinsic suitability of some definite outcome from a presupposed situation" (PR 207), derived from the judger's prehension of the primordial nature of God, in which eternal objects are graded in degrees of relevance to actual occasions. Such an "intuition of suitability" provides the basis for the probabilistic prediction of novel occurrences in the future and for man's uncanny sense for the right hypothesis. "There will be nothing statistical in this suitability. It depends upon the fundamental graduation of appetitions which lies at the base of things, and which solves all indeterminations of transition" (PR 207).

Thus, by refusing to separate the experimenter from the experimental situation, the judger from the data judged, Whitehead can objectively ground both inductive and derivative judgments without losing sight of their subjectivity and fallibility.

\section{VII • Process: AN OvervieW}

To put the complexities of the previous analyses in proper perspective, the various functionings described must be reinserted in the fundamental model of the concrescence of an actual occasion, of a drop of experience. An actual entity arises out of its actual world via a process in which objectivity is gradually transformed into subjective immediacy, which is to say, into the final integration of every element in the ideal and real realms and of every element arising in the concrescence. The data originally felt as alien are integrated in the conformal phase of this process by means of selective objectifications whereby they become a unified (but still not private) datum susceptible for further integration. Thus the initial phase of any concrescence is characterized by receptivity, re-enactment, reiteration. In the various phases of the supplemental stage, this public datum is met with private feelings arising in accordance with the private ideal of the occasion. The scalar overwhelms the vector; physical feeling loses its pre-eminence to the burgeoning conceptual feelings. In the aesthetic portion of the supplement, emo- 
tional and purposive subjective forms transmute the objectively given into the subjectively appropriated: the alien becomes the personal; the datum is appreciated, enjoyed; its elements are adjusted in importance through intensifications and inhibitions. But the phase is "blind." Pure intellectuality - the pure grasp of eternal objects in themselves-is not as yet functional. The conceptual feelings in the aesthetic supplement grasp the eternal objects as tied to and exemplified in the particularity of the datum. Hence physical purposes may arise but neither propositional feelings nor consciousness. But this "blindness" itself must be integrated into the concrescing subject. The occasion must take a determinate stand with respect to its blindness: either by ratifying it and thus reaching satisfaction as a personal, subjective re-enactment of objectivity, or by refusing to ratify it and thus opening up the possibility of intellectual supplementation, with its inrush of propositional and comparative (conscious) feelings. When these intellectual feelings have exhausted the possibilities of integration and comparison (which are a function of the order-disorder in the data), the concrescence "closes up," reaches the satisfaction of a fully determinate drop of novel, private experience, and perishes to be a new datum for further synthesis. In its process, it has both satisfied the urge of the creativity that "all may be one," and provoked a transition to future creative activity. 